This item was submitted to Loughborough's Research Repository by the author.

Items in Figshare are protected by copyright, with all rights reserved, unless otherwise indicated.

\title{
The effects of activated carbon surface features on the reactive adsorption of carbamazepine and sulfamethoxazole
}

PLEASE CITE THE PUBLISHED VERSION

http://dx.doi.org/10.1016/j.carbon.2014.08.081

\section{PUBLISHER}

(C) Elsevier

\section{VERSION}

AM (Accepted Manuscript)

\section{PUBLISHER STATEMENT}

This work is made available according to the conditions of the Creative Commons Attribution-NonCommercialNoDerivatives 4.0 International (CC BY-NC-ND 4.0) licence. Full details of this licence are available at: https://creativecommons.org/licenses/by-nc-nd/4.0/

\section{LICENCE}

CC BY-NC-ND 4.0

\section{REPOSITORY RECORD}

Nielsen, Lilja, Mark J. Biggs, William Skinner, and Teresa J. Bandosz. 2019. "The Effects of Activated Carbon Surface Features on the Reactive Adsorption of Carbamazepine and Sulfamethoxazole". figshare. https://hdl.handle.net/2134/25140. 


\section{The effects of activated carbon surface features on the reactive adsorption of carbamazepine and sulfamethoxazole}

Lilja Nielsen ${ }^{\text {a }}$, Mark J. Biggs ${ }^{b}$, William Skinner ${ }^{\text {, }}$, Teresa J. Bandosz ${ }^{\text {a,* }}$

${ }^{\mathrm{a}}$ The City College of New York and the Graduate School of CUNY

Department of Chemistry and Department of Earth System Science

160 Convent Ave, New York, NY 10031

b The University of Adelaide

School of Chemical Engineering

Adelaide, SA 5005, Australia

${ }^{\mathrm{c}}$ University of South Australia

Ian Wark Research Institute and The ARC Special Research Centre for Particle and Material

Interfaces, Mawson Lakes, Adelaide, SA 5095, Australia

\footnotetext{
*Whom correspondence should be addressed to. E-mail:tbandosz@ccny.cuny.edu; Tel.:(212)650-6017; Fax (212) 650-6107
} 


\begin{abstract}
Two commercial carbons, coconut shell- and wood-based were chosen to evaluate the mechanisms of carbamazepine (CBZ) and sulfamethoxazole (SMX) adsorption from low (ppm level) concentration of these pharmaceuticals. The initial sample and those after adsorption were extensively characterized using potentiometric titration, thermal analysis combined with mass spectroscopy, FTIR, and XPS. It was found that not only porosity but also surface chemistry plays an important role in the adsorption process. The results show that extensive surface reactions take place during adsorption and adsorbates undergo significant transformations in the pore system. The ability of carbon surfaces to form superoxide ions results in the oxidation of CBZ and SMX, and their partial decomposition. Surface chemistry also promotes dimerization of the latter species. Moreover, functional groups of CBZ and SMX, mainly amines, react with oxygen groups of the carbon surface. Thus not only microporous carbons with sizes of pores similar to those of adsorbate molecules, but the carbons with large pores, rich in oxygen groups, can efficiently remove these pharmaceuticals following the reactive adsorption mechanism.
\end{abstract}

\title{
1. Introduction
}

Removal of pharmaceuticals and their metabolites from water has become an important challenge for contemporary society. Even though they are usually present at very low concentrations of a few ppb, their long term effect on human health and on aqueous organisms can be detrimental [1]. Therefore, it is generally accepted that an increased attention should be put on the removal of these compounds from waste-water and drinking water [2, 3]. Adsorption on powdered activated carbons (PAC) is a traditional and well-known method of water purification. However, as undesired pharmaceuticals and their metabolites are usually present in 
very small concentrations (ppb), the 'standard' activated carbons may not be sufficient to achieve the desired water purity. Even though ozonation is an often used alternative method to remove micropollutants from water, recent reports suggest that, for the purpose of drinking water purification, adsorption on activated carbons may be 'safer' as it does not lead to undesired oxidation-derived products [4].

Recently biochars have been investigated as water purification media [5-7]. There is practically no difference between these materials and activated carbons, generally and from the points of view of a porous structure and surface chemistry; essentially only the names differ. In fact, organic precursors of activated carbons are often "bio" materials, for instance, wood or peat. The literature on the removal of pharmaceuticals on activated carbons is quite extensive [8-11]. To evaluate their adsorption performance a dose amount [12], surface charge [13], polarity [7] and porosity [14] are the most often considered parameters. It is well known that the latter is of paramount importance for any physical adsorption process [15]. In pores similar in size to the adsorbate molecules, the dispersive interactions are enhanced and the efficiency of the separation process increases. On the other hand, polarity provides specific interactions when the adsorbate is polar [16]. The $\mathrm{pH}$ of water from which the pharmaceuticals have to be removed and the $\mathrm{pH}_{\mathrm{PZC}}$ of the carbon surface are also important since a change in $\mathrm{pH}$ can cause a deprotonation/protonation of certain functional groups on the molecule and carbon surface leading to a change in charge on the groups. [17].

Considering all the findings published to date on the role of activated carbon surfaces in pharmaceutical removal $[10,18]$, the objective of this paper is a detailed analysis of the role of 
the surface functional groups, mainly oxygen-containing, and their location in the pore system, on the adsorption process. As target pharmaceuticals carbamazepine (CBZ) and sulfamethoxazole (SMX) are chosen. The latter is a sulfonamide bacteriostatic antibiotic used often to treat urinary infections whilst carbamazepine is an anti-seizure medicine. The molecular masses are similar (253 g/mol for SMX and $236 \mathrm{~g} / \mathrm{mol}$ for CBZ) and their sizes and boiling points are also comparable. A significant difference is in their chemical composition. Carbamazepine $\left(\mathrm{C}_{15} \mathrm{H}_{12} \mathrm{~N}_{2} \mathrm{O}\right)$ contains an amide group and nitrogen present in a cyclic ring (azepane). Sulfamethoxazole $\left(\mathrm{C}_{10} \mathrm{H}_{11} \mathrm{~N}_{3} \mathrm{O}_{3} \mathrm{~S}\right)$ on the other hand, exhibits more linear shape with sulfone and amine moiety linking amino-substituted cyclohexane and a methylated isoxazolidine. The $\mathrm{pK}_{\mathrm{a}}$ value for CBZ is 13.90 [19] and for SMX 1.7 and 5.6 [12]. Thus differences in the specific interactions/reactive adsorption are expected. To evaluate the role of these interactions in the separation process, two commercial activated carbons were chosen. They differ significantly in their pore structure and surface chemistry. Taking into account their features and the adsorptive performance, the mechanism of the adsorption process is proposed. The results are expected to cast some new light on the importance of activated carbons fine surface features/chemical groups and their distribution in the pore system for the effective removal of micropollutants of various chemistries. 


\section{Experimental}

\subsection{Materials}

\subsubsection{Chemicals}

Carbamazepine (CBZ) was obtained from Sigma-Aldrich (St. Louis, MO) and sulfamethoxazole (SMX) from Spectrum (USA) with a purity of $\geq 98 \%$ and $99 \%$, respectively. Their detailed chemical formulas are presented below:<smiles>NC(=O)N1c2ccccc2C=Cc2ccccc21</smiles>

Red $=$ urea Molecule is a dibenazepin<smiles>Cc1cc(NS(=O)(=O)c2ccc(N)cc2)no1</smiles>

Red $=$ amine Blue $=$ sulfonamide Purple $=$ isoxazole

\subsubsection{Adsorbents}

As adsorbents, two commercial activated carbons were chosen. WVA-1100 is a wood based carbon manufactured by Mead-Westvaco. This carbon was obtained using chemical activation with phosphoric acid. Another adsorbent chosen is S208C, manufactured by Calgon Carbon. This carbon was obtained from coconut shells by physical activation. The carbons are referred to as WVA and S208.

\subsection{Methods}

2.2.1 FT-IR spectroscopy. Fourier transform infrared (FT-IR) spectroscopy was carried out using a Nicolet Magna-IR 830 spectrometer using the attenuated total reflectance (ATR) method. The 
spectrum was generated and collected 64 times and corrected for the background noise. The experiments were done on the powdered samples, without $\mathrm{KBr}$ addition.

2.2.2.Thermal analysis/mass spectroscopy. Thermogravimetric (TG) curves were obtained using a TA Instruments (2950 Thermogravimetric) thermal analyzer. The initial and exhausted samples were exposed to an increase in temperature $\left(10{ }^{\circ} \mathrm{C} / \mathrm{min}\right)$ while the nitrogen flow rate was held constant (100 mL/min). From the TG curves, differential DTG curves were derived. Simultaneously the gasified products desorbed from the surface of the adsorbents were identified by a ThermoStar Gas Mass Spectrometer (GSD; Pfeiffer Vacuum)), connected to the thermal analyzer. The off-gas collected was scanned with a secondary electron multiplier (SEM) detector and a Faraday detector. The molecules identified in the MS were correlated in real time with its corresponding temperature in the TA.

2.2.3. Potentiometric titration. Potentiometric titration measurements were performed with a DMS Titrino 716 automatic titrator (Metrohm). The instrument was set at the mode where the equilibrium $\mathrm{pH}$ is collected. Subsamples of the initial materials $(\sim 0.100 \mathrm{~g})$ were added to $\mathrm{NaNO}_{3}(0.01 \mathrm{M}, 50 \mathrm{~mL})$ and placed in a container maintained at $25{ }^{\circ} \mathrm{C}$ overnight for equilibrium. During the titration the suspension was continuously saturated with $\mathrm{N}_{2}$ to eliminate the influence of atmospheric $\mathrm{CO}_{2}$. The suspension was stirred throughout the measurements, and each sample acidified to $\mathrm{pH} 3$ before titration. Volumetric standard $0.1 \mathrm{M} \mathrm{NaOH}$ was used as the titrant of the materials suspension up to $\mathrm{pH}$ 11. The experimental data was transformed into a proton binding curve, Q, representing the total amount of protonated sites. Then the SAIEUS deconvolution [20] procedure was applied to calculate the $\mathrm{pK}_{\mathrm{a}}$ distributions of the acidic species present on the surface of the adsorbents. 
2.2.4.Surface $p H$. A $0.1 \mathrm{~g}$ sample of dry adsorbent was added to $5 \mathrm{~mL}$ of deionized water and the suspension stirred overnight to reach equilibrium. The $\mathrm{pH}$ of suspension was measured using an Accumet Basic pH meter (Fisher Scientific).

2.2.5. XPS. X-ray photoelectron spectroscopy analyses of the carbons were conducted using a Kratos Axis-Ultra spectrometer, using a monochromatic Al Ka source (1487 eV) operating at 15 $\mathrm{kV}$ and $14 \mathrm{~mA}, 10^{-8} \mathrm{~Pa}$ vacuum in the analyser chamber and an analysis spot size of $300 \times 700$ $\mu \mathrm{m}$. Spectrometer pass energy of $40 \mathrm{eV}$ was used for all elemental spectral regions, whilst 160 eV pass energy was used for the survey spectra used for surface atomic concentration calculation. The binding energy scale of spectrometer was calibrated using the metallic $\mathrm{Cu} 2 \mathrm{p}_{3 / 2}$ and $\mathrm{Cu} 3 \mathrm{p}_{3 / 2}$ lines and Au Fermi Edge of the respective reference metals. All measurements were performed at a take-off angle of $90^{\circ}$. The CasaXPS (version 2.3.5) and Multipack software was used to fit photoelectron spectra. Many organic materials, and their surfaces, contain species that are sensitive to prolonged X-ray exposure, particularly under ultra-high vacuum conditions. In all analyses presented in this study, the sample stage temperature was reduced to less than $-120{ }^{\circ} \mathrm{C}$ using a liquid nitrogen cooling system. This has been shown to preserve the chemical environment of matrix and adsorbed elements for periods far longer than data collection times [21], even with X-ray intensities experienced on synchrotron sources [22].

2.2.7. Adsorption of pharmaceuticals. Kinetic studies were conducted in a shaker bath (100 rpm at $30{ }^{\circ} \mathrm{C}$ ) using $0.05 \mathrm{~g}$ of activated carbon with $100 \mathrm{~mL}$ of a pharmaceutical compound solution (100 mg/L). Samples were filtered at time points ranging from 0 to 72 hours, and the concentration of pharmaceutical compounds in the filtrate was determined by high-performance liquid chromatography (Waters 2695) with a Licrocart C18 column. A mobile phase consisted of 
$65 \%$ methanol and 35\% trifluoroacetic acid (0.1\%) for use in the case of CBZ, and $35 \%$ methanol and $65 \%$ trifluoroacetic acid (0.1\%) for SMX.

Batch adsorption tests were conducted to determine equilibrium isotherms. $250 \mathrm{~mL}$ Erlenmeyer flasks with $0.05 \mathrm{~g}$ activated carbon and $200 \mathrm{~mL} \mathrm{CBZ} \mathrm{or} \mathrm{SMX} \mathrm{solutions} \mathrm{at} 8$ concentrations (1$100 \mathrm{mg} / \mathrm{L})$ were placed in a shaker bath $\left(100 \mathrm{rpm}\right.$ at $\left.30^{\circ} \mathrm{C}\right)$ for 72 hours. Samples were filtered and the filtrate analyzed for pharmaceutical concentrations as outlined above. The equilibrium adsorption capacity was calculated, and then fitted to the Langmuir-Freunlich equation:

$\theta_{t}=q_{e} / q_{0}=\left(K C_{e}\right)^{n} / 1+\left(K C_{e}\right)^{n}$

where $C_{e}$ is the equilibrium concentration $(\mathrm{mg} / \mathrm{L}), q_{o}$ the maximum amount adsorbed $(\mathrm{mmol} / \mathrm{g})$, $K$ is the adsorption equilibrium constant $(\mathrm{L} / \mathrm{mg})$, and $n$ is a parameter related to the energetic heterogeneity of the adsorption sites.

\section{Results and Discussion}

\subsection{Adsorption kinetics}

The results of the adsorption kinetic studies are presented in Fig. 1S in Supplementary Information. Adsorption equilibrium on WVA was reached more rapidly than that on S208, which might be related to a difference in porosity and surface chemistry between these two carbons. Based on the kinetics studies the equilibration time was chosen as 72 hours for the adsorption of both adsorbates on both adsorbents. The results also indicate that CBZ is adsorbed faster than SMX, which suggests a more complex adsorption process of the latter species. 


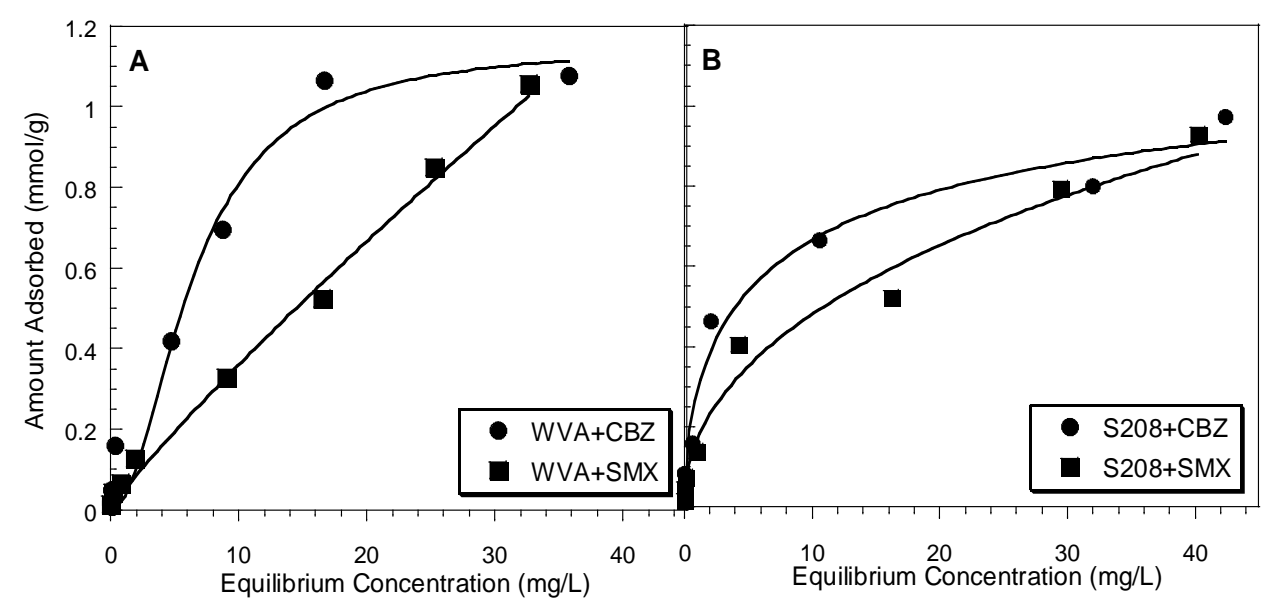

Fig. 1. SMX and CBZ adsorption isotherms on the WVA (A) and S208 (B) carbons. The solid lines represent the goodness of the fit to L-F equation.

\subsection{Analysis of the adsorption isotherms}

The adsorption isotherms are collected in Fig. 1. In the case of WVA adsorbent, significant differences in the shapes of the isotherms for the two adsorbates are visible. While the isotherm for SMX is almost linear, CBZ is rather adsorbed following the Langmuir-Freundlich adsorption isotherm model where the high-energy centers are responsible for a steep rise in the amount adsorbed at low surface coverage. Even though at low equilibrium pressure more CBZ than SMX is adsorbed on WVA, the linear shapes of the SMX isotherm suggests that at higher concentrations more of this species will be retained than CBZ. Both CBZ and SMX exhibit similar shapes of the isotherms on S208 indicating the presence of a significant amount of the high-energy adsorption centers. Then the gradual occupation of the centers with decreasing adsorption energy takes place. Even though on S208 at very low surface coverage slightly more CBZ is adsorbed than SMX, overall the surface of this carbon has higher affinity to remove the 
latter species (Figure 1, Table 1). With an increasing coverage (equilibrium concentration) on both carbons more SMX is adsorbed than CBZ. These results do not agree with those published in the literature, where higher hydrophobicity of CBZ was considered by Serrano and co-workers as an enhancing factor for its adsorption on activated carbons [23]. On the other hand, Li and coworkers found the similar amounts adsorbed of both compounds in the range of $280 \mathrm{~g} / \mathrm{g}$ [24]. These values are not far from the measured amounts adsorbed on our carbons. However, Li and co-workers also pointed out that the efficiency of CBZ removal was higher than that of SMX owing to higher hydrophobicity of this compound.

Table 1. Fitting parameters of the experimental data to Langmuir-Freundlich equation.

\begin{tabular}{lccccc}
\hline \multicolumn{2}{c}{ Sample } & $q_{0}[\mathrm{mmol} / \mathrm{g}]$ & $K[1 / \mathrm{mg}]$ & $n$ & $R^{2}$ \\
\hline WVA & & & & & \\
& CMZ & 1.41 & 0.1124 & 1.10 & 0.9799 \\
& SMX & 63.57 & 0.0003 & 0.89 & 0.9930 \\
\hline S208 & & & & 0.9761 \\
& CMZ & 1.27 & 0.1181 & 0.58 & 0.9809 \\
& SMX & 7.51 & 0.0004 & 0.48 & \\
\hline
\end{tabular}

The results of fitting the experimental isotherms to Langmuir-Freundich model are collected in Table.1. The order of magnitude difference in the maximum adsorption capacity of SMX on WVA is related to almost linear shape of the isotherm on the latter sample. This is also visible in an $n$ value close to 1 . Since the $n$ values smaller than 1 indicate the energetic heterogeneity of the adsorption system, the results suggest that SMX adsorption on S208 involves the most complex mechanism. 


\subsection{Adsorption mechanism}

To understand the adsorption mechanism and especially the role of specific interactions/reactive adsorption, the surfaces of our carbons and changes in these surfaces after interactions with the target adsorbates have to be analyzed in detail. Even though some results on the porosity and surface chemistry of WVA [25] and S208 [26] have been published and analyzed while addressing the adsorption mechanism of other species, we consider that for better understanding of our system, the summary of some these data has to be reintroduced to this paper.

Table 2. The parameters of porous structure for the initial carbons calculated from nitrogen adsorption isotherms.

\begin{tabular}{lcccccc}
\hline Sample & $\begin{array}{c}\mathrm{S}_{\mathrm{BET}} \\
{\left[\mathrm{m}^{2} / \mathrm{g}\right]}\end{array}$ & $\mathrm{V}_{\text {mic }}\left[\mathrm{cm}^{3} / \mathrm{g}\right]$ & $\begin{array}{c}\mathrm{V}_{\text {mic }}<10 \AA \\
{\left[\mathrm{cm}^{3} / \mathrm{g}\right]}\end{array}$ & $\begin{array}{c}\mathrm{V}_{\text {meso }} \\
{\left[\mathrm{cm}^{3} / \mathrm{g}\right]}\end{array}$ & $\mathrm{V}_{\mathrm{t}}\left[\mathrm{cm}^{3} / \mathrm{g}\right]$ & $\mathrm{V}_{\text {mic }} / \mathrm{V}_{\mathrm{t}}$ \\
\hline WVA & 1648 & 0.61 & 0.11 & 0.54 & 1.15 & 0.53 \\
S208 & 1042 & 0.40 & 0.27 & 0.13 & 0.53 & 0.75 \\
\hline
\end{tabular}

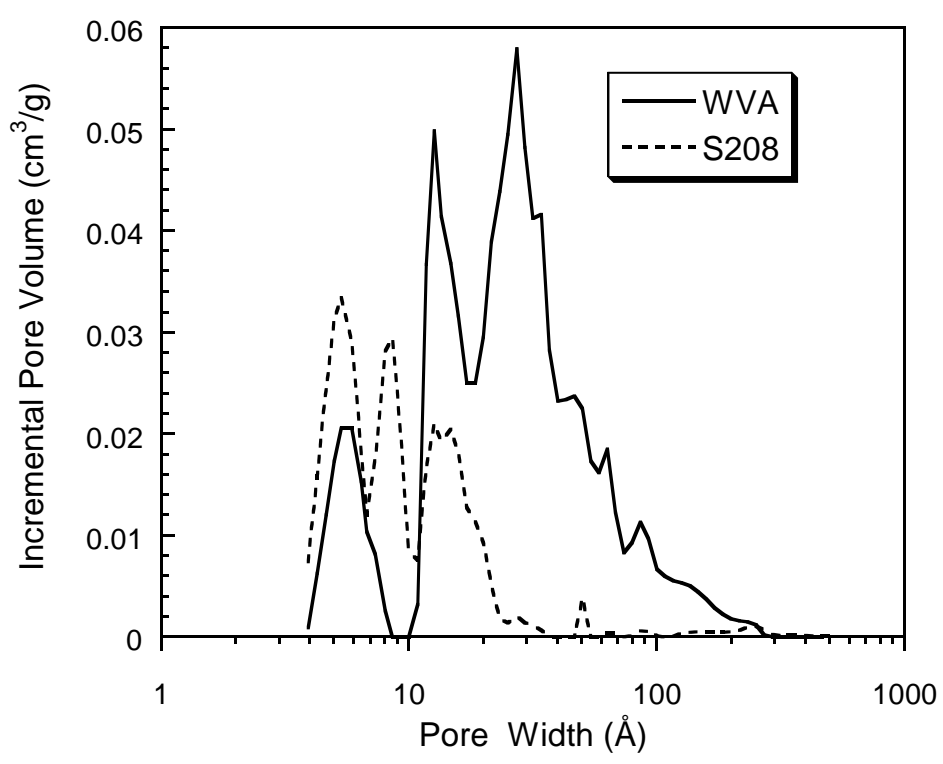

Fig. 2. Pore size distributions for the carbons studied. 
For every adsorption system for removal of a micropollutant, the porosity of the adsorbent should be of paramount importance. Table 2 collects the parameters of the porous structure calculated from nitrogen adsorption isotherms. The surface area of WVA is $60 \%$ larger than that of S208. A similar trend (50 \% difference) is found for the volume of micropores. On the other hand, the volume of pores smaller than $10 \AA$ is $40 \%$ higher in S208 than that in WVA. While the smallest pores should be more active in physical adsorption and they create high-energy physical adsorption centers, functional groups can exist only in larger pores and thus they may affect the surface interaction at higher surface coverages [27]. Thus the porous structure of WVA might be more favorable for specific interactions/reactive adsorption than that of S208, providing that the active surface chemistry exists in large pores.

The details on pore size distributions are seen in Fig. 2. In S208 almost all pores are smaller than $20 \AA$ and its degree of microporosity is $75 \%$. WVA has a significant volume of pores larger than $20 \AA$. The range of pore sizes for this carbon reaches $300 \AA$. The trends in the amounts adsorbed of each adsorbate on both carbons are largely unrelated to the differences in the surface areas or volumes of micropores. The only clearly visible trend is more SMX adsorbed on WVA than that on S208, which might suggest that large micropores/mesopores and the extent of their volume are important for the adsorption of this species. CBZ is considered as much more hydrophobic than SMX and the trend in its amounts adsorbed might agree with the predominance of dispersive interactions. Nevertheless, the shapes of the isotherms indicate that the surface interactions with CBZ are stronger in WVA than those in S208. This behavior would not be expected taking into account that much smaller pores are present in the latter sample and they 
should enhance the adsorption potential for dispersive interaction. Therefore, there should be other specific/chemical factors, which affect the adsorption mechanism of CBZ on WVA.

The isotherm of SMX on WVA shows a linear trend (Fig. 1), which might be related to the occupation of the highest energy adsorption centers at the concentration range used for our experiments. They might be specific functional groups undergoing reactions with SMX. On the other hand, one has to take into account that the dispersive adsorption forces for SMX in the pores larger than 2-3 diameters of this molecule (small mesopores) should be rather weak and they are not expected to contribute significantly to the adsorption process, if only dispersive interactions play a role.

The fact that based on LF-fitting much more CBZ than SMX can be adsorbed on S208, in spite of similar molecular sizes and masses, suggests that some chemical forces are involved in the adsorption process of the target pharmaceuticals. At low surface coverage the isotherms overlap but with an increasing coverage the differences are seen. With the increasing coverage the larger pores are filled where the functional groups can exist and they must contribute to the specific interactions of CBZ with the S208 surface. This is an interesting observation taking into account that CBZ has only two moieties (from the urea part of the molecule), which can interact in a specific way with surface functional groups. 

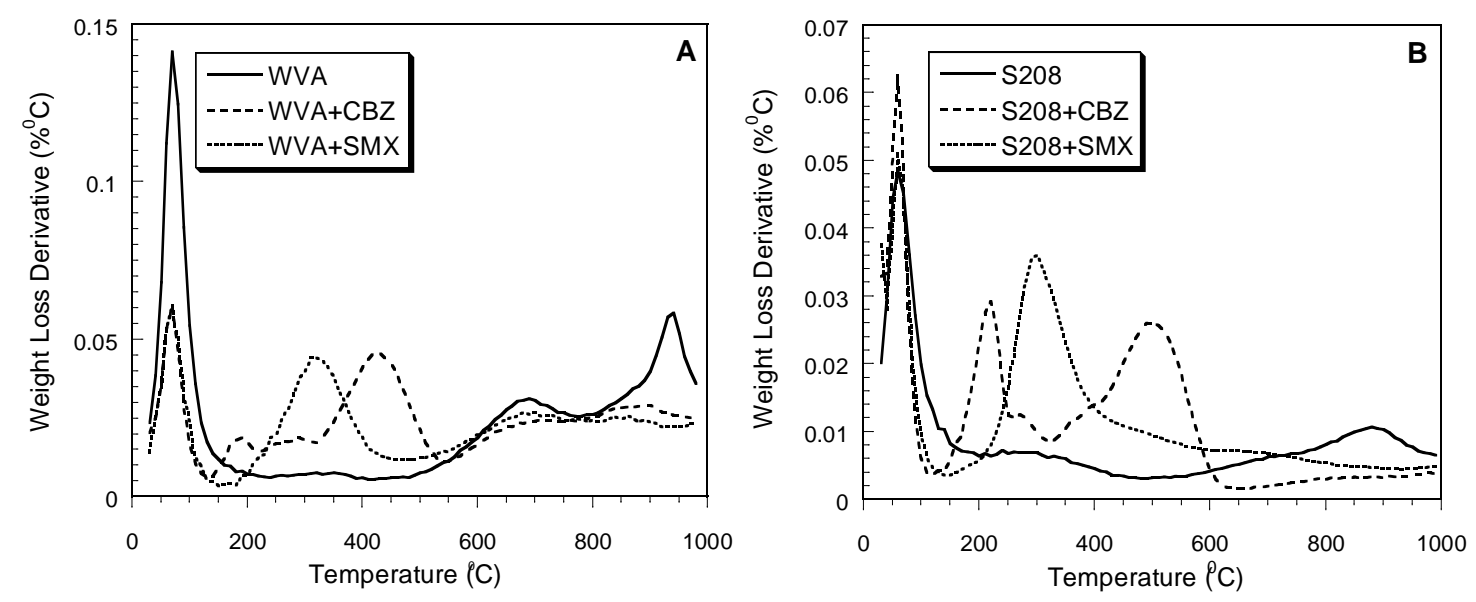

Fig. 3. DTG curves in nitrogen for WVA (A) and S208C (B) initial carbons and those after SMX and CBZ adsorption.

Thermal analysis of the initial carbons and those exposed to CBZ and SMX can bring valuable information about the mechanism of adsorbates' interactions with the adsorbents' surfaces. The DTG curves, where the peaks represent the weight losses related to desorption/decomposition of surface species either adsorbed or chemically bound are collected in Fig. 3. For comparison, and to eliminate any effect of possible solvent-adsorbent chemical interactions TA experiments were also run on the carbons exposed to water. No changes after water adsorption were noticed in comparison with the initial samples. When the thermal decomposition of pure CBZ and SMX was tested, the weight loss was observed as a two-component peak between $200-400{ }^{\circ} \mathrm{C}$ (Fig. S2 of Supplementary Information). Interestingly, the main weight loss for both adsorbates is between their melting $\left(190{ }^{\circ} \mathrm{C}\right.$ for CBZ and $166{ }^{\circ} \mathrm{C}$ from SMX) and boiling points $\left(411{ }^{\circ} \mathrm{C}\right.$ for CBZ and $482{ }^{\circ} \mathrm{C}$ for SMX ) (http://www.lookchem.com) which suggests some degree of their sublimation. For SMX adsorbed on both carbons similar weight loss patterns are found with the 
main peak between $200-400{ }^{\circ} \mathrm{C}$ and the long tail almost through a whole temperature range. The tail is also visible on the decomposition pattern of pure SMX, which we link to its dimerization [28] during heating and to the decomposition of the dimers/polymers formed. This is because the ratio of its intensity to the intensity of the main peak on the carbons studied is much greater than for the pure substances. Since this effect is especially visible for S208, it suggests that dimerization may be partially responsible for the smaller adsorption of SMX than that of CBZ caused by an inaccessibility of the small pores of S208 to the dimers formed, and by blocking the pore entrances with these surface reaction products. The weight loss pattern for WVA over 600 ${ }^{\circ} \mathrm{C}$ was not analyzed since this carbon was not exposed to these temperatures during its production. Much as for S208, we link the first peak on the DTG curve for WVA exposed to SMX to the removal of physically adsorbed SMX and the enhanced tail to the decomposition of the species formed as a result of its dimerization/polymerization and chemical interactions with surface groups of carbons. Even though we cannot comment on the involvement of carboxylic groups in these reactions owing to overlapping of their decomposition temperatures [29] with that of SMX decomposition, the involvement of groups decomposing between 800 and $1000{ }^{\circ} \mathrm{C}$, probably phenols [30], is seen.

Interestingly, the desorption patterns from the carbons with CBZ adsorbed on the surface are much more complex than those for SMX. On the DTG curve for S208 two peaks are revealed, at about $200{ }^{\circ} \mathrm{C}$ and between 450 and $600{ }^{\circ} \mathrm{C}$. Moreover, an indication of peaks is also seen at about 270 and $370{ }^{\circ} \mathrm{C}$. Since we cannot expect that adsorbed species in their unreacted form decompose/sublimate at a lower temperature than those in the bulk, we link the low temperature peak at $200{ }^{\circ} \mathrm{C}$ to the changes in the chemistry of adsorbed species, caused likely by oxidation 
reactions. It is well known that an activated carbon surface catalyzes the formation of superoxide ions [31]. These ions could oxidize urea moiety in some CBZ molecules resulting in the formation of either urea, or when oxidation goes further, of ammonia and $\mathrm{CO}_{2}$ [32]. The narrow peak indicates the chemical homogeneity of the species desorbed and the temperature range rather suggests that urea is formed. It starts to decompose at about $150{ }^{\circ} \mathrm{C}$ [33] and when adsorbed in small pores the higher temperature of weight loss associated with this process can be observed. Then the carbamazepine and phenanthrene, the latter which might be the product of oxidative surface reactions, are removed. In the broad temperature range between $400{ }^{\circ} \mathrm{C}$ and $600{ }^{\circ} \mathrm{C}$ thermal transformations of strongly adsorbed/reacted with carbon surface CBZ takes place and the removal of decomposition products is detected. The large shift in the removal temperature suggests the existence of the specific interaction of CBZ with the carbon surface. The consumption of the oxygen groups decomposed at higher temperature in surface reactions is also noticed in this case. They could be quinones, which are known as participating in oxygen activation [34] or groups reacting directly with amine groups of CBZ as phenols.

A weight loss pattern for CBZ on WVA differs from that for S208. A broad peak between 100 and $500{ }^{\circ} \mathrm{C}$ is revealed with visible three components with maxima at 190,290 and $430{ }^{\circ} \mathrm{C}$. The last component is likely CBZ reacted with the carbon surface. Its removal temperature is lower than that for S208 owing to the larger micropore sizes in WVA than those is S208 and thus less energy needed to remove the adsorbate retained on the surface. The peak at $290{ }^{\circ} \mathrm{C}$ might represent the removal of CBZ physically/weakly adsorbed in the pore system. The first peak at $190{ }^{\circ} \mathrm{C}$, as in the case of S208, must represent the removal of the product of CBZ reactive adsorption, likely urea. Apparently on this carbon the extent of chemical surface transformations 
is different since the intensity of the low temperature peaks is much smaller than that for the peak at $430{ }^{\circ} \mathrm{C}$. The high intensity of the latter peak suggests the reactive adsorption of CBZ on the surface of this carbon.

More qualitative information about the desorption/decomposition of the products adsorbed on the surface of our carbons can be derived from the analysis of $\mathrm{m} / \mathrm{z}$ thermal profiles of the species removed from the surface. They are collected in Fig. 4. Only m/z 15, 17, 48 and 64 were chosen since they relate to heteroatoms of the adsorbates and on their patterns some visible changes after CBZ and especially, SMX adsorption were noticed. These profiles can represent $\mathrm{CH}_{3}$ and/or $\mathrm{NH}$, $\mathrm{NH}_{3}$ and/or $\mathrm{OH}, \mathrm{SO}$ and $\mathrm{SO}_{2}$, respectively. These species are expected to be released when CBZ (only first two of them) or SMX (all of them) decompose/are desorbed from the surface. Thus CBZ adsorption on S208 results in the release of water and ammonia at temperatures lower than $200{ }^{\circ} \mathrm{C}$. The high temperature shoulder likely represents the latter species originated from the decomposition of urea. The $\mathrm{m} / \mathrm{z}$ profiles are featureless at high temperature, even though the well defined weight loss is found between $400-600{ }^{\circ} \mathrm{C}$ (Fig. 3). The absence of signals might be related to the removal of high molecular weight products of surface reactions, which are not detected by our MS (m/z limit is 100). After SMX adsorption, the removal of ammonia at low temperature is detected indicating that some decomposition reactions take place on the surface. The peak from the removal of $\mathrm{SO}_{2}$ is noticed between 250 and $450{ }^{\circ} \mathrm{C}$ with the maximum at 350 ${ }^{\circ} \mathrm{C}$. This overlaps with the most intense weight loss for this sample, which was linked to the removal sublimation and boiling of SMX. Some traces of SO are also removed at temperatures over $800{ }^{\circ} \mathrm{C}$ and it must be related to the removal of dimers and thermal transformations of sulfones on the surface. 
In the case of the initial WVA sample, the most intense peak at m/z 17 represents the removal of physically adsorbed water and water from the decomposition of carboxylic acids. Adsorption of CBZ decreases the intensity of the peak, which might be related to the involvement of the carboxylic acids in the surface reactions with the urea moiety. The lack of signals on the analyzed $\mathrm{m} / \mathrm{z}$ thermal profiles at the temperature ranges where significant weight losses were measured, suggests that either other fragments representing hydrocarbons (not chosen for analysis) are released, or $\mathrm{m} / \mathrm{z}$ are too large to be detected by our mass spectrometer. 


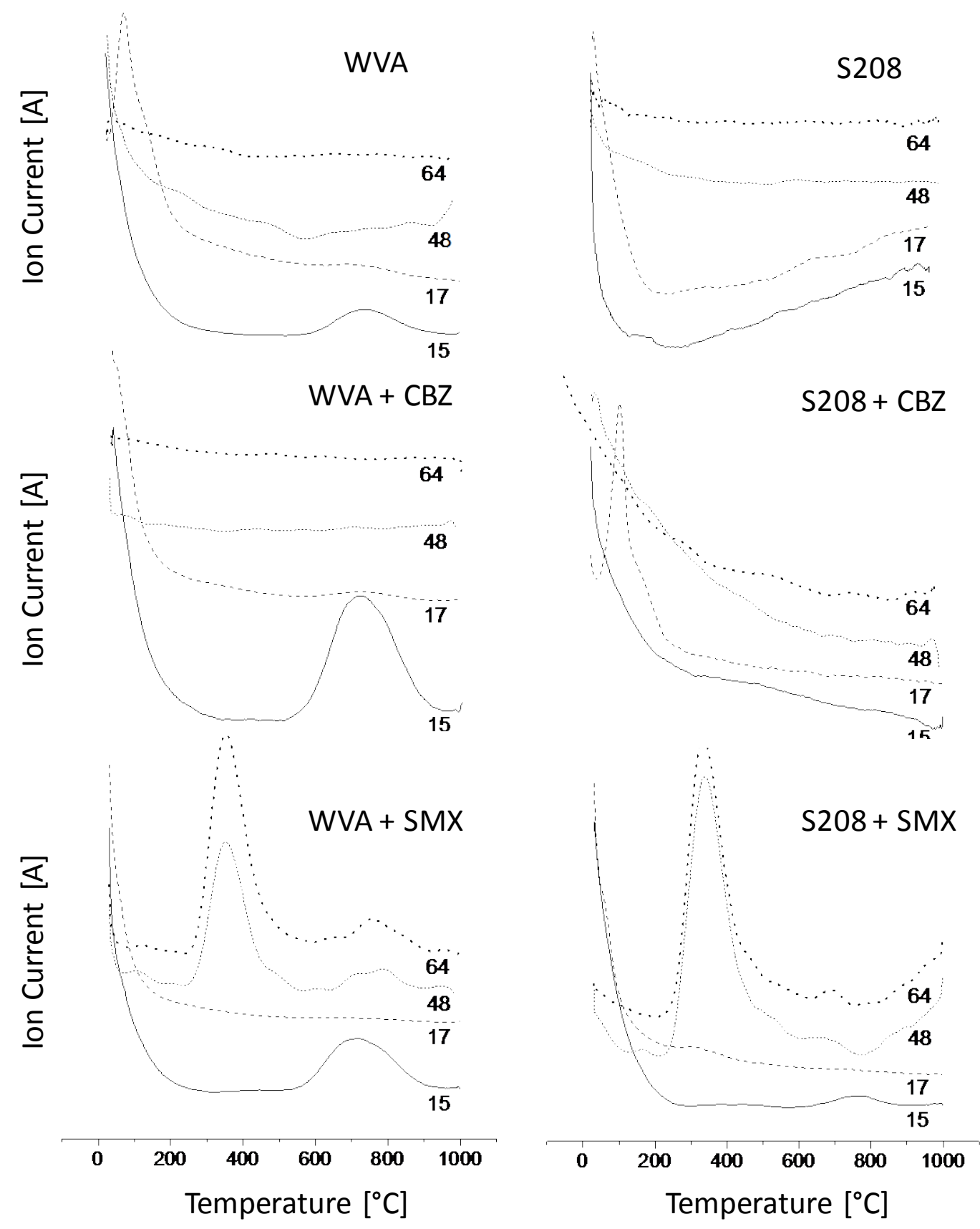

Fig. 4. MS patterns during thermal analysis in helium for carbons WVA and S208. 

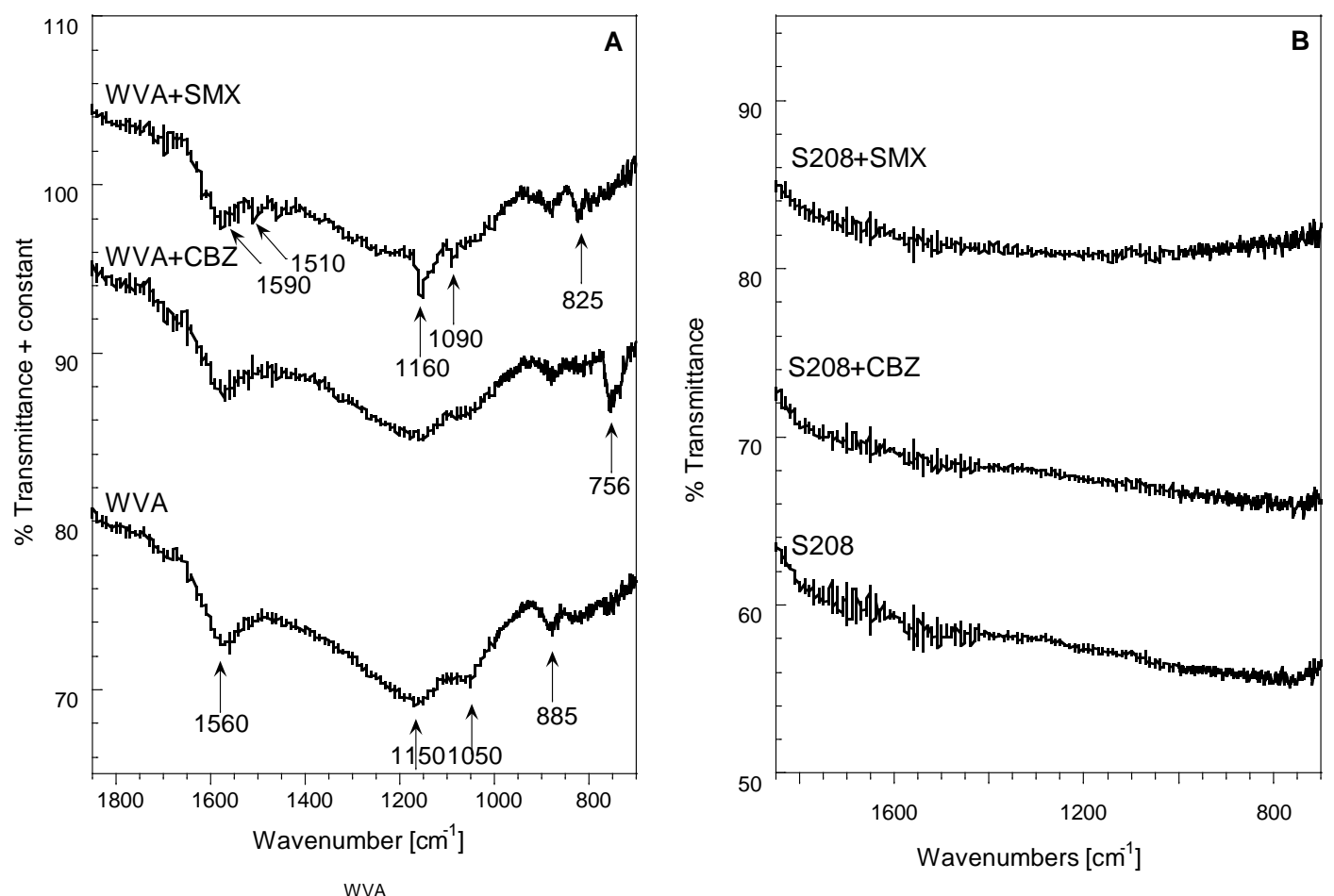

Fig. 5. Comparison of FTIR spectra for the initial carbons, WVA (A) and S208 (B), and those after SMX and CBZ adsorption.

The results of FTIR analysis are presented in Fig. 5. Unfortunately, the data for S208 cannot be interpreted and the featureless spectra obtained are due to a high level of condensation of aromatic rings in this carbon, which results in absorption of almost all infrared radiation. On the other hand, on the spectra for the WVA series several bands can be clearly distinguished. On the spectrum for the initial sample the bands visible at 1560, 1150, 1050 and $885 \mathrm{~cm}^{-1}$ (as indicated by arrows in Fig. 5) represent quinones, carboxyl and carbonates, C-O, and C-H vibrations, respectively. After $\mathrm{CBZ}$ adsorption the intensities of bands related to carbon oxygen groups 
decrease and a new strong band appears at $756 \mathrm{~cm}^{-1}$, which corresponds to the $\mathrm{NH}_{2}$ out-of-planebend [35]. SMX adsorption, besides decreasing the intensity of the $\mathrm{C}-\mathrm{O}$ and $\mathrm{C}=\mathrm{O}$ bands, also results in the appearance of new bands at 1590, 1510, 1160, 1090 and $825 \mathrm{~cm}^{-1}$. They are linked to the presence of $\mathrm{C}=\mathrm{N}, \mathrm{C}-\mathrm{N}, \mathrm{N}-\mathrm{H}$, and $-\mathrm{SO}_{2}$ - bonds [36]. The appearance of these bands and the decrease in the intensity of carbon-oxygen bands, especially those at $1560 \mathrm{~cm}^{-1}$ and $1050 \mathrm{~cm}^{-1}$ representing quinones and C-O bonds, supports the reactivity of SMX and CBZ with this carbon surface.
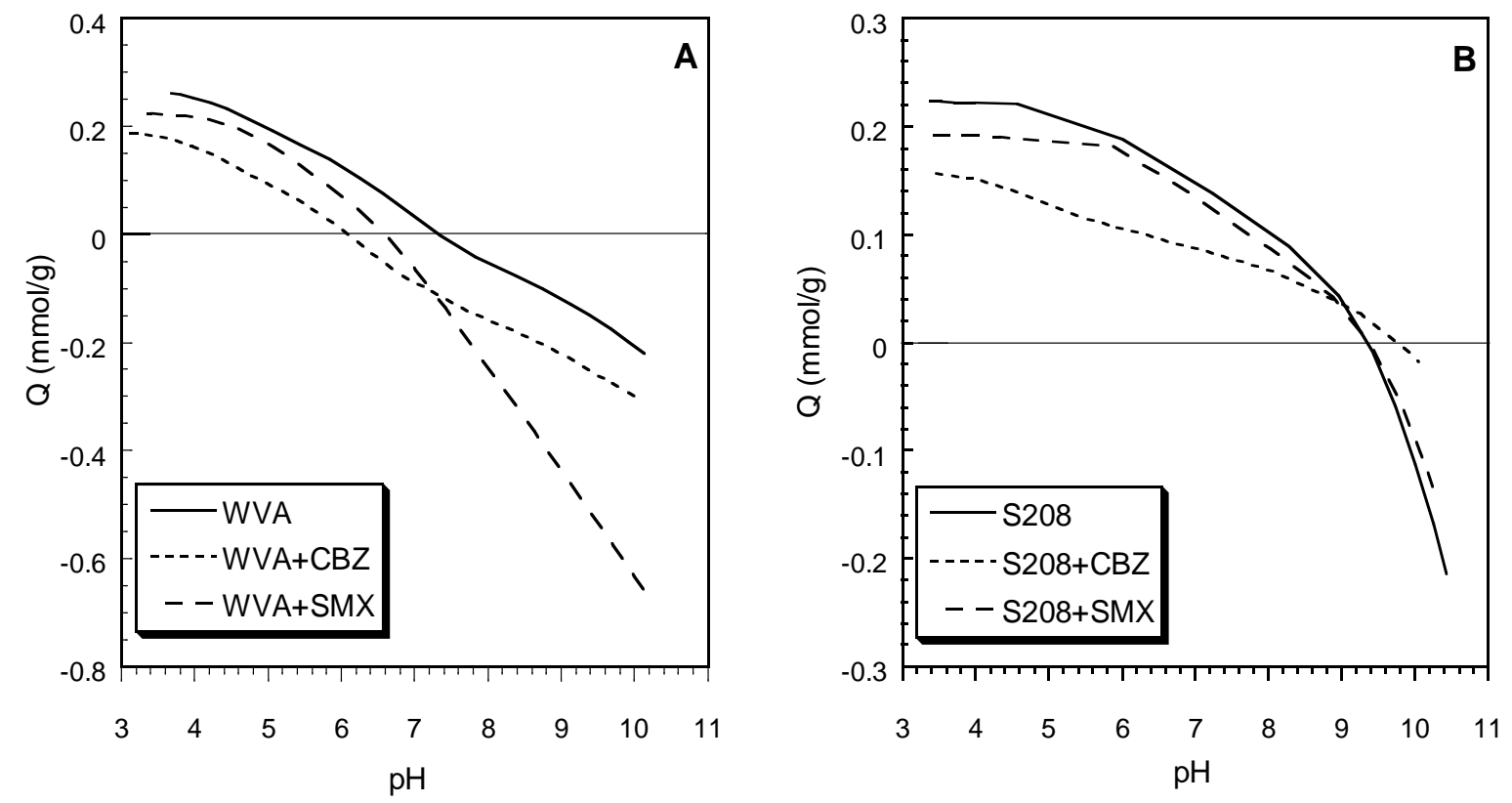

Fig. 6. Proton uptake curves for WVA (A) and S208 (B) initial adsorbents and those exposed to carbamazepine (CBZ) and sulfamethoxazole (SMX). 
Potentiometric titration results confirm the differences in the chemistry of WVA and S208 carbons (Fig. 6). Positive values of $\mathrm{Q}$ represent a proton uptake on basic groups and a negative proton release from the acidic groups [37]. The $\mathrm{pH}_{\mathrm{PZC}}$ for WVA is 7.4 and for $\mathrm{S} 208$ it is 8.5, indicating higher basicity of the latter sample. After exposure to $\mathrm{CBZ}$ and SMX the $\mathrm{pH}_{\mathrm{PZC}}$ values decrease for WVA and the shape of the proton uptake curve after adsorption of SMX is significantly altered, indicating an increase in surface acidity. It looks like the surface groups dissociating at pH> 5 are introduced. When SMX is adsorbed on the S208 only a small decrease in the amount of basic groups dissociating at $\mathrm{pH}<6$ is noticed. On the other hand, a significant change in the acidity of the surface after CBZ adsorption is seen. The total number of acidic groups decreases, and the surface become more basic. This is an important observation suggesting different binding mechanism of SMX and CBZ on the surfaces of both carbons. Interestingly, while adsorption of CBZ on WVA does not change in a marked way the nature of surface acidic groups, on the surface of S208 a significant number of groups are involved in surface reactions (Fig. 7). This supports the data from TA analysis which showed the consumption of groups which decompose at high temperatures, and which might represent phenols with $\mathrm{pK}_{\mathrm{a}}$ greater than 9. 


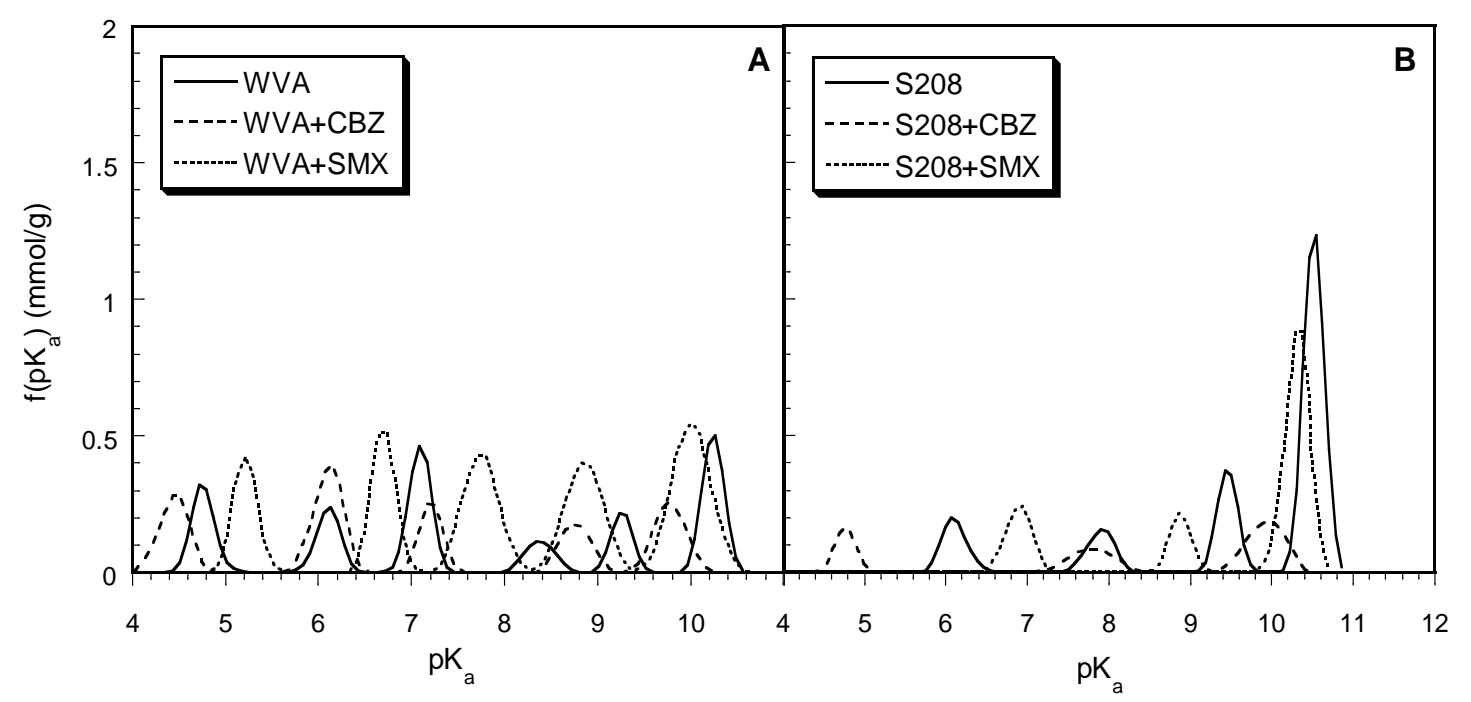

Fig. 7. The comparison of the $\mathrm{pK}_{\mathrm{a}}$ distributions for the initial and spent carbons, WVA (A) and S208 (B).

Details on the exact position of the peak and the number of groups represented by a particular peak are collected in Table 1S of Supplementary Information. The total number of groups detected on the surface of S208, S208-CBZ and S208-SMX is 0.665, 0.226 and $0.511 \mathrm{mmol} / \mathrm{g}$, respectively. In the case of WVA, WVA-CBZ and WVA-SMX these amounts are 0.586, 0.541 and $1.023 \mathrm{mmolg} / \mathrm{g}$, respectively. Once again, these results show the differences in the surface reactivity of both carbons with our target adsorbates. For the initial carbons, the groups dissociating at $\mathrm{pK}_{\mathrm{a}}<7$ are considered as carboxylic and those in $\mathrm{pK}_{\mathrm{a}}>7$ - as phenolic [37]. After CBZ adsorption a species of strong acidity appears on the surface of both carbons and they might represent protonated $-\mathrm{NH}_{2}$ entities or other protonated nitrogen-containing species, for instance, pyridine ( $\mathrm{pK}_{\mathrm{a}}$ 5.25) [38] (Fig. 7). A shift in the $\mathrm{pK}_{\mathrm{a}}$ values, especially after SMX adsorption, on both carbons supports their surface reactivity with this species. Adsorption of SMX results in much more pronounced changes on both carbons than those caused by CBZ. Even though the 
number of groups dissociating in the whole $\mathrm{pH}$ range increases, the most marked changes are visible at $\mathrm{pK}_{\mathrm{a}}$ greater than 7. Apparently adsorption of SMX resulted in acidification of the samples. These acids were introduced to the surface probably due to the protonation of the nitrogen group of the sulfamide moiety. The number of groups on WVA increased by 0.437 $\mathrm{mmol} / \mathrm{g}$. This number cannot be directly related to the amount adsorbed since in reactive adsorption the consumption of some groups is expected, as was clearly seen on the DTG curves (Fig. 3). In fact, taking into account that the surface of WVA is rich in carboxylic groups, their reactions with amines of SMX likely took place, resulting in the formation of species such as amides and water. Oxidation of sulfones to sulfonic acids is also a plausible scenario. Moreover, phenolic groups can react with amines leading to the formation of aniline and the corresponding alcohol. The carboxylic groups of the surface can also catalyze other transformations involving the products of CBZ oxidation.

Taking into account the $\mathrm{pH}_{\mathrm{PzC}}$ of both our carbons is greater than 7 , and the experiments were run in water without adjusting the $\mathrm{pH}$, the surface of carbons should be positively charged, favoring adsorption of anions via electrostatic interactions [12]. Considering the chemistry of our molecules, we do not expect these kinds of interactions to play a predominant role in the adsorption process. Therefore the dispersive and polar interactions, or surface reactions, will be considered in derivation of the adsorption mechanism. 
Table 3. Content of elements on the surface (in atomic \% from XPS analysis).

\begin{tabular}{lcccccc}
\hline Sample & $\mathrm{C}$ & $\mathrm{O}$ & $\mathrm{N}$ & $\mathrm{S}$ & $\mathrm{P}$ & $\mathrm{Na}$ \\
\hline S208 & 92.6 & 7.4 & ND & ND & ND & ND \\
S208+CBZ & 91.4 & 6.5 & 2.1 & ND & ND & ND \\
S208+SMX & 90.3 & 7.9 & 1.6 & 0.25 & ND & ND \\
WVA & 89.9 & 8.4 & ND & ND & 0.59 & 1.08 \\
WVA+CBZ & 89.5 & 8.2 & 1.8 & ND & 0.42 & ND \\
WVA+SMX & 88.7 & 9.1 & 1.8 & 0.37 & ND & ND \\
\hline
\end{tabular}

To further support the hypothesis discussed above, the XPS analysis of the initial carbons and those with adsorbed CBZ and SMX were carried out. The elemental compositions, in atomic \%, on the surface of our carbons are presented in Table 3. S208 is richer in carbon in C-C bonds and has less oxygen than WVA which is in agreement with the results discussed above. The trace of $\mathrm{P}$ and Na in WVA are the results of its activation with phosphoric acid followed by neutralization during the manufacturing process of this carbon. After adsorption of SMX the ratio of nitrogen to sulfur on WVA is 4.9, and on S208 is 6.4. Taking into account that this ratio in SMX is 3:1, these results suggest significant transformations of the adsorbate on the surface towards incorporation of stable nitrogen. This is especially visible for the WVA carbon. More nitrogen and sulfur on the surface of this carbon can be also linked to its higher affinity to retain SMX than that of S208. After CBZ adsorption the nitrogen content on the surface of S208 is greater than that on WVA. Since the differences in the adsorption capacities between these two carbons are rather small we link these differences to the reactivity of WVA surface. It is possible that some nitrogen got released from the surface as a result of urea oxidation to ammonia and $\mathrm{CO}_{2}$. 
The complexity of the chemical environment of nitrogen remaining on the surface is evidenced from the deconvolution of N1 s core energy level for the carbons after CBZ adsorption (Table 4, Fig. 8). Apparently pyridine species are formed, and the ratio of conversion from amines is much greater on WVA than that on S208. The results support the hypothesis formulated based on the results of surface analyses discussed above. Thus ammonia evolved from the decomposition of the carbamazepine/urea moiety must contribute to pyridine functionality formation in the acidic environment of these carbon nanoreactors/pores. On the other hand, the conversion of nitrogen groups to pyridine in the case of SMX reactive adsorption is similar on both carbons. Interestingly, in the case of the adsorption of these species on S208, the conversion rate for SMX is higher than that for CBZ. Since an acidic environment catalyzes pyridine formation, the appearance of sulfonic acids on this carbon can trigger these transformations. Oxidation of sulfones to sulfonic acids is even more pronounced on S208 than on WVA (Fig. 8), which may be linked to the formation of superoxide ions, and enhanced electron transfer on a more aromatized carbon surface. The presence of sulfones/sulfonic acid is also visible in an increase in the oxygen content after SMX adsorption. However, the content of oxygen decreased after CBZ adsorption and it must be linked to the above-mentioned consumption of some oxygen groups in surface reactions. 

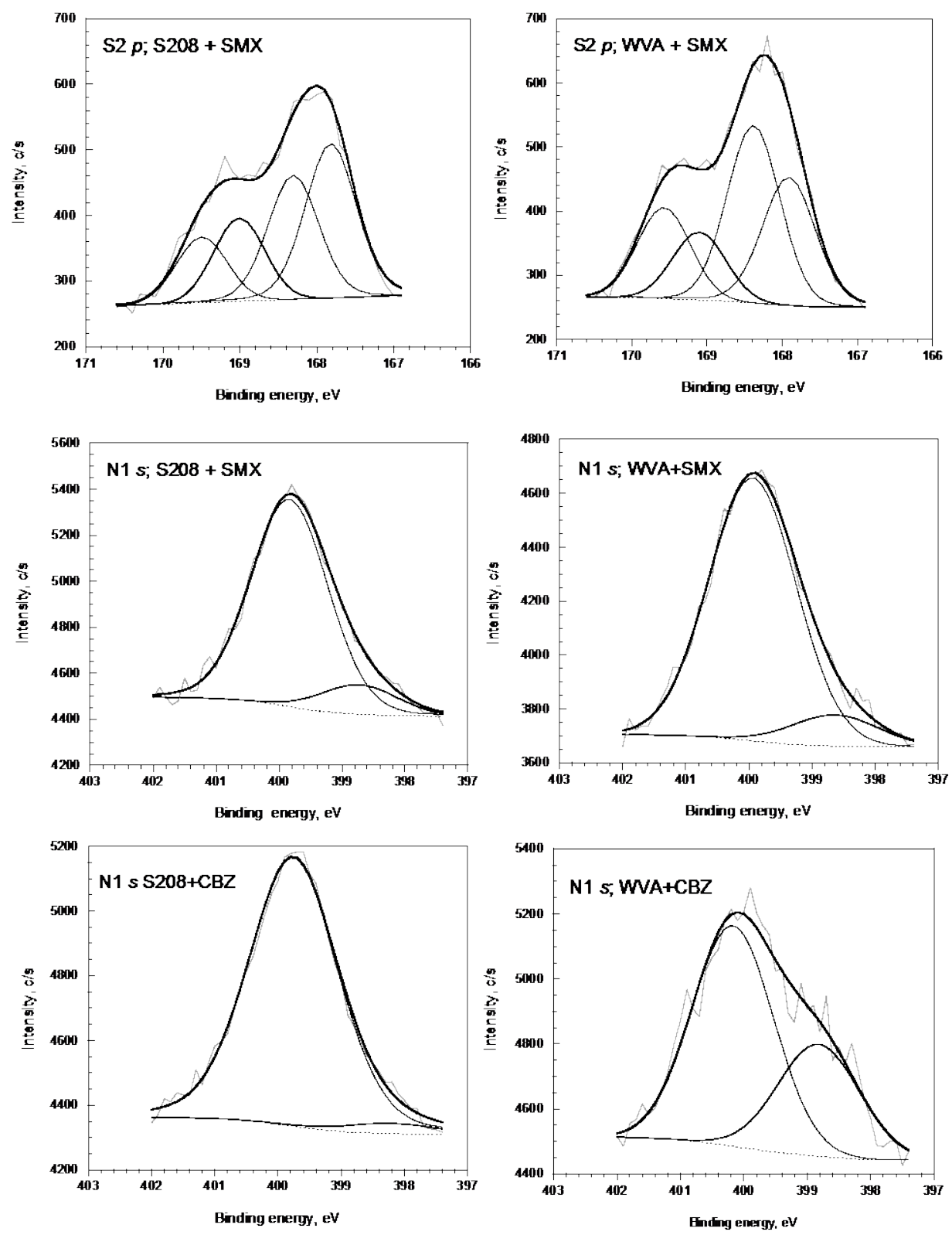

Fig. 8. Deconvolution of S2 $p$ and N1 s core energy levels for the carbons studied with adsorbed SMX and CBZ 
Table 4. The results of deconvolution of C $1 s, \mathrm{O} 1 s, \mathrm{~N} 1 s$ and S $2 p$ core energy levels.

\begin{tabular}{|c|c|c|c|c|c|c|c|}
\hline \multirow{2}{*}{$\begin{array}{l} \\
\text { Energy, } \\
\text { eV }\end{array}$} & \multirow[b]{2}{*}{ Bond assignment } & \multicolumn{3}{|c|}{$\begin{array}{c}\text { S208 } \\
\end{array}$} & \multicolumn{3}{|c|}{ WVA } \\
\hline & & Initial & $+\mathrm{CBZ}$ & + SMX & Inital & $+\mathrm{CBZ}$ & +SMX \\
\hline \multirow{2}{*}{$\begin{array}{l}\text { C 1s } \\
284.8 \\
285.9\end{array}$} & \multirow{4}{*}{$\begin{array}{l}\mathrm{C}-(\mathrm{C}, \mathrm{S}) \text { (graphitic carbon) } \\
\mathrm{C}-(\mathrm{O}, \mathrm{N}, \mathrm{H}) \text { (phenolic, alcoholic, } \\
\text { etheric) } \\
\mathrm{C}=\mathrm{O} \text { (carbonyl or quinone) } \\
\mathrm{O}-\mathrm{C}=\mathrm{O} \text { (carboxyl or ester) }\end{array}$} & 83.7 & 84.3 & 81.6 & 86.9 & 83.1 & 87.0 \\
\hline & & 11.6 & 10.5 & 13.0 & 7.2 & 9.6 & 9.1 \\
\hline 286.9 & & 4.7 & 5.3 & 5.4 & 3.6 & 4.6 & 4.6 \\
\hline 288.7 & & & & & 2.2 & 2.8 & \\
\hline \multirow{3}{*}{$\begin{array}{l}\mathrm{O} 1 \mathrm{~s} \\
530.7 \\
532.1\end{array}$} & \multirow{4}{*}{$\begin{array}{l}\text { Ketone, lactone, carbonyl } \\
\mathrm{O}=\mathrm{C} / \mathrm{O}=\mathrm{S} \text { (in carboxyl/carbonyl or } \\
\text { sulfoxides/ sulfones) } \\
\mathrm{O}-\mathrm{C} \text { (in phenol/epoxy, ether, ester, } \\
\text { anhydride, carboxyls }\end{array}$} & & & & & & \\
\hline & & 43.5 & 22.2 & & 37.7 & 22.0 & 20.9 \\
\hline & & 56.5 & 33.7 & 57.0 & 34.5 & 48.3 & 47.8 \\
\hline 533.6 & & & 44.1 & 43.0 & 27.8 & 29.7 & 31.3 \\
\hline \multirow{2}{*}{$\begin{array}{l}\mathrm{N} 1 \mathrm{~s} \\
398.7 \\
400.2\end{array}$} & \multirow{2}{*}{$\begin{array}{l}\text { N-6 (in pyridine) } \\
\text { N-5 (in pyrrolic/pyridone and amide, } \\
\text { amines) }\end{array}$} & & 3.7 & 11.9 & & 33.7 & 10.5 \\
\hline & & & 96.3 & 88.1 & & 66.3 & 89.5 \\
\hline $\begin{array}{l}\mathrm{S} 2 p_{3 / 2} \\
167.8\end{array}$ & $\begin{array}{l}\mathrm{R}_{2}-\mathrm{S}=\mathrm{O} / \mathrm{R}-\mathrm{SO}_{2}-\mathrm{R} \text { (in sulfoxides, } \\
\text { sulfones) }\end{array}$ & & & 56.0 & & & 42.7 \\
\hline 168.3 & R-SO ${ }_{3} \mathrm{H}$ (in sulfonic acids) & & & 44.0 & & & 57.3 \\
\hline
\end{tabular}

Thus, based on the above, disproportionation of the amide bond of carbamazepine with a subsequent release of phenanthrene and urea can take place on the surface of our carbons as a result of oxidation with superoxide ions formed in the process of oxygen activation [31]: 


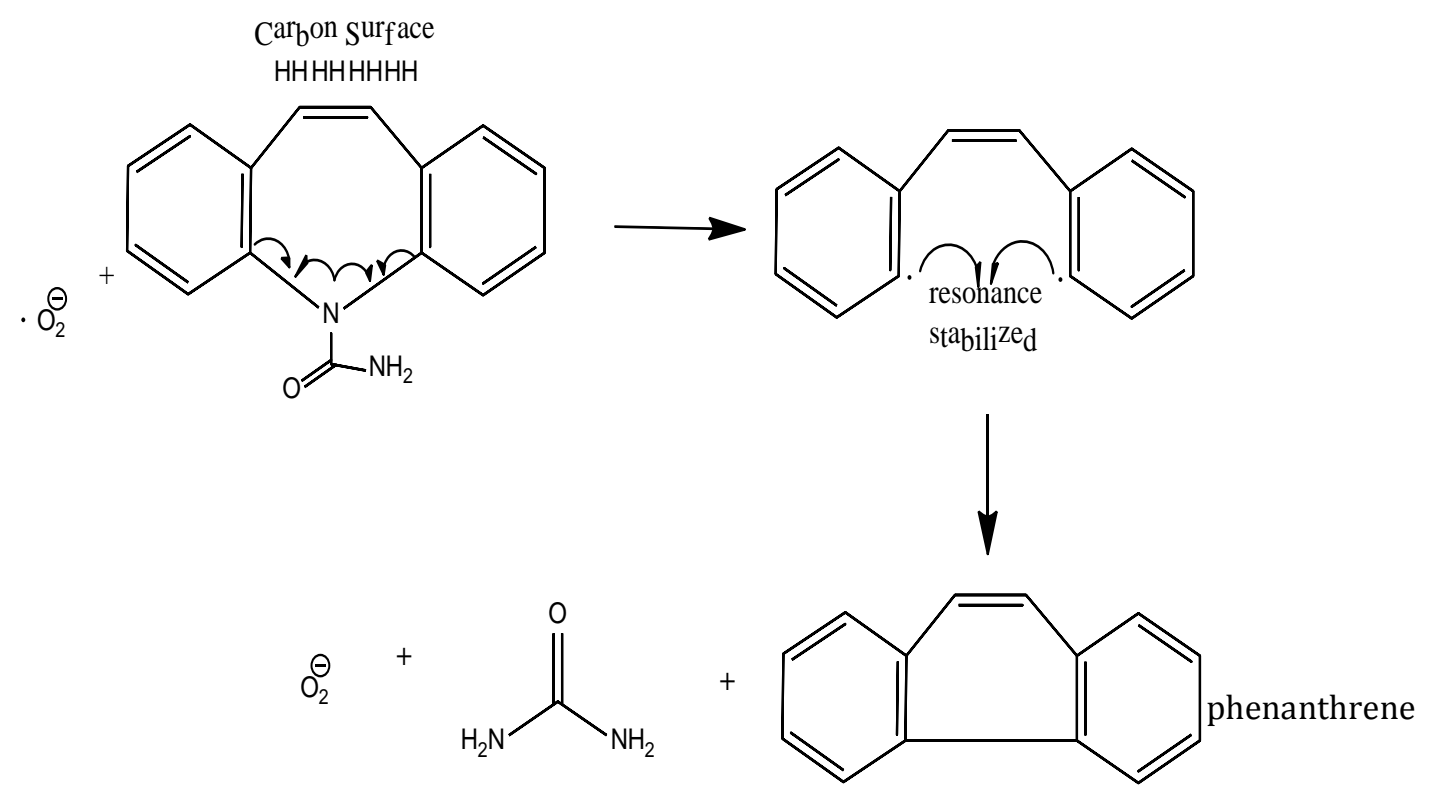

That disproportionation of the amide bond of carbamazepine can even go further and $\mathrm{NH}_{3}$ and $\mathrm{CO}_{2}$ can be released:

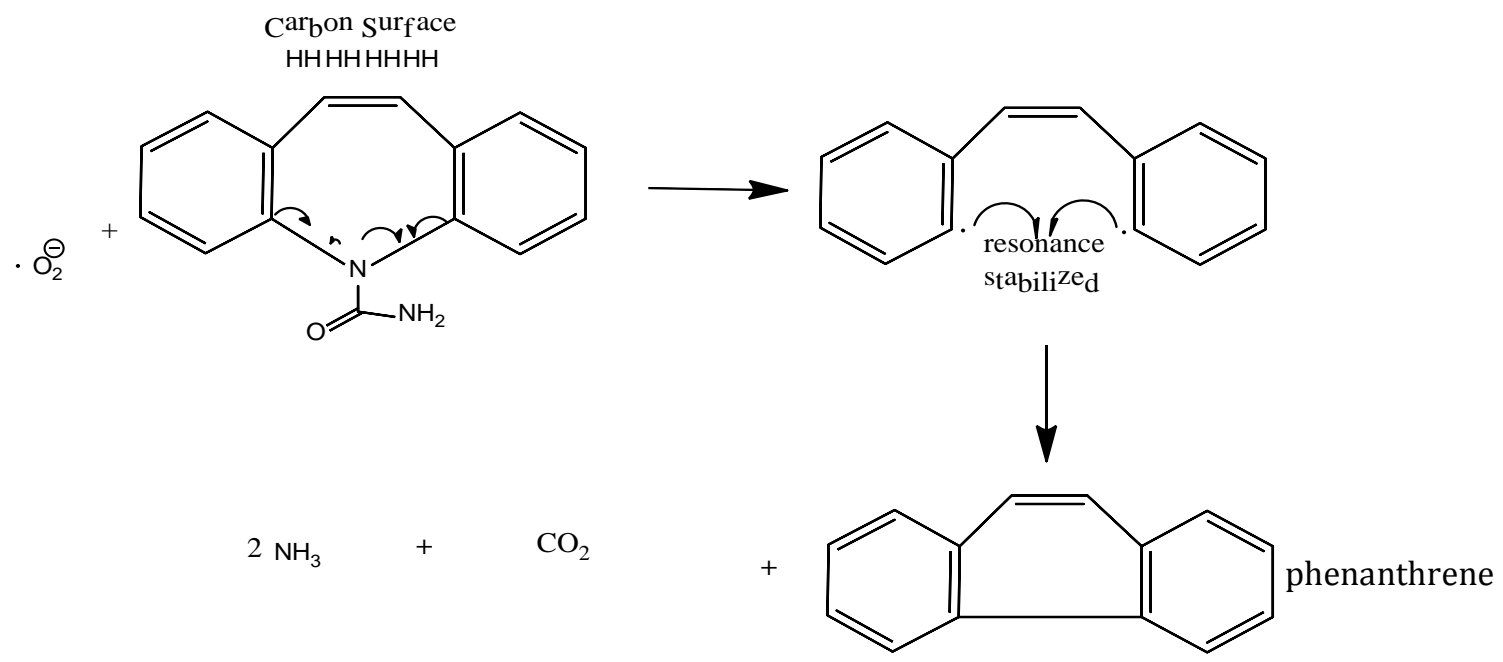

Released ammonia can be incorporated the aromatic ring on the surface of carbons, especially for WVA which has a low degree of aromatization and is rich in oxygen species such as aldehydes and carboxylic acids. 
Another obvious scenario is the reactions of amine groups of CBZ with surface carboxylic acids. The reaction is also expected to take place in the case of SMX:

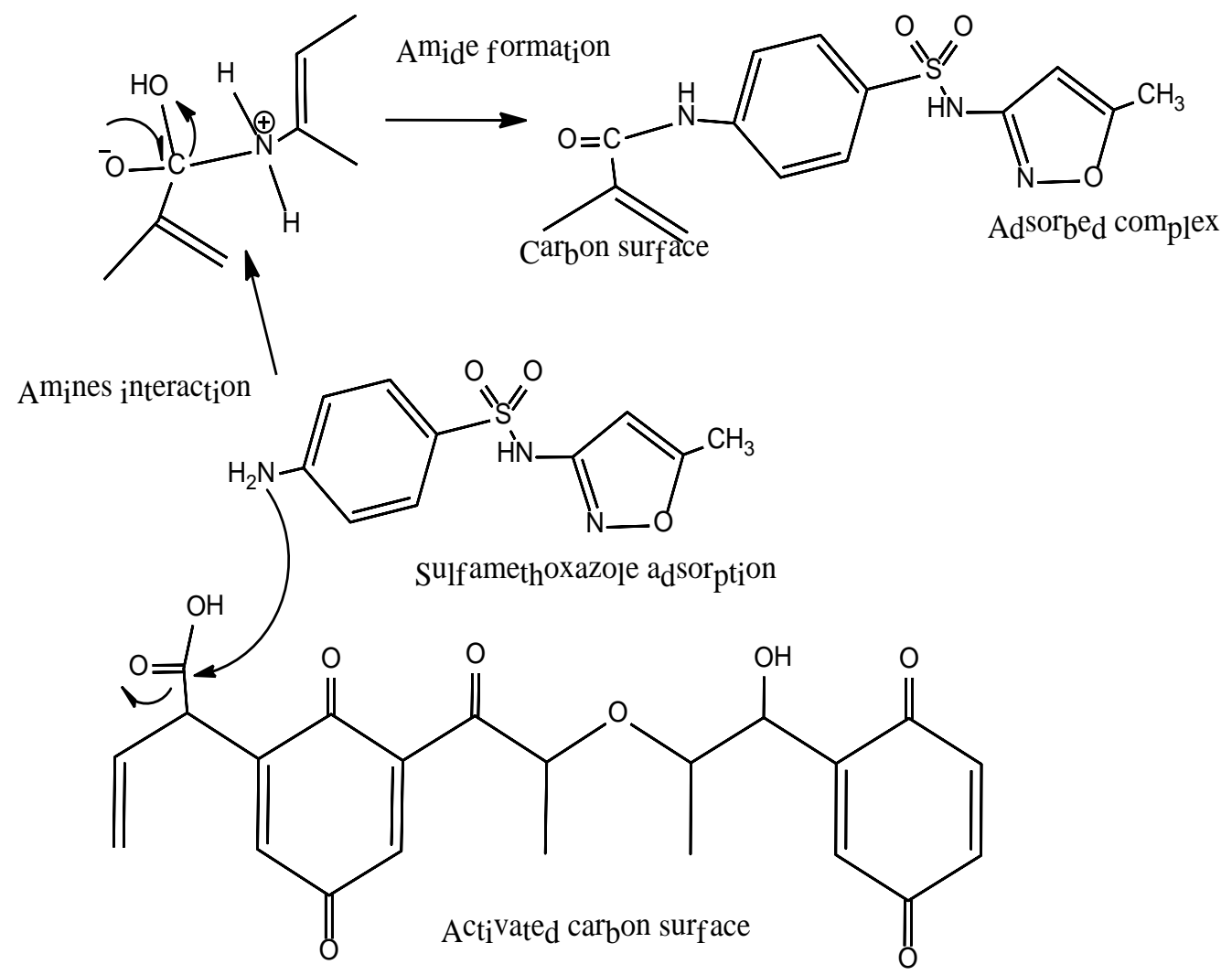

Moreover, the results suggest amide formation is occurring and that superoxide ions are able to oxidize sulfones to sulfonic acid, accompanied by the breaking of S-N bonds.

A decrease in the number of high temperature decomposing groups (Carbonyl/quinones/phenols) can be explained by their reactions with amine moieties of our adsorbates: 


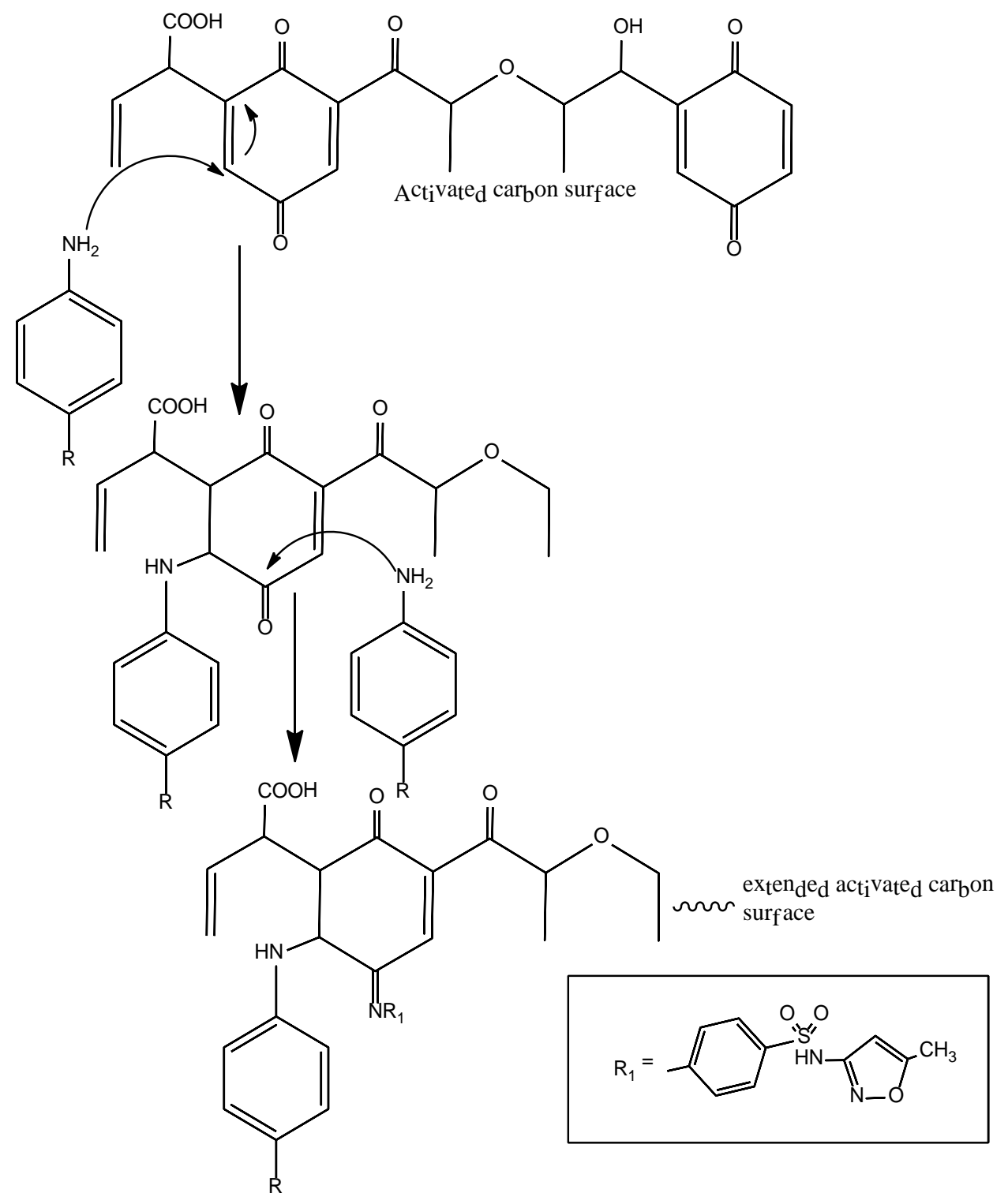




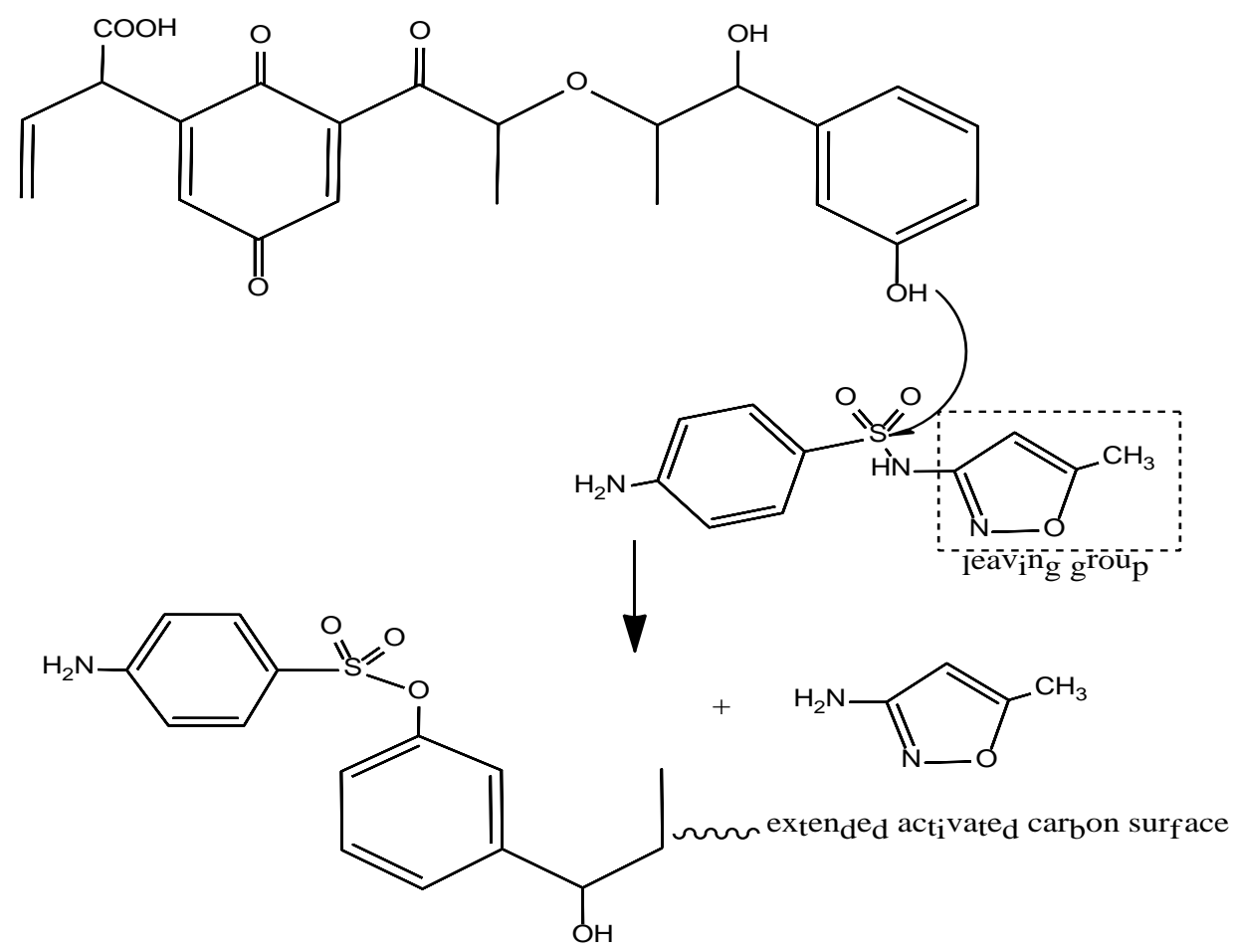

\section{Conclusions}

The results presented in this paper show that not only the charge on the pollutant molecules and their level of hydrophobicity should be considered as important parameters governing their adsorption capacity on activated carbons. We have shown for the first time that depending on the chemical affinity between the adsorbate and the carbon surface, important transformations of the adsorbed molecules determined as reactive adsorption take place. This is owing to the oxygen groups incorporated to the carbon matrix. These species, besides attracting polar molecules, also react with functional groups of the pollutants, especially with amines, resulting in very strong adsorption forces/covalent bonds. Moreover, the ability of a carbon surface to activate oxygen results in the partial oxidation of the adsorbed species. Dimerization is also a possible surface reaction, especially in the case of SMX. Since these oxygen-containing groups should exist in large micropores and in mesopores where dispersive interactions are rather weak, they enhance significantly the ability of activated carbons to remove these functional micropollutants. 


\section{Acknowledgement}

This publication was made possible by USEPA grant (RD835178). Its contents are solely the responsibility of the authors and do not necessarily represent the official views of the USEPA. Furthermore, USEPA does not endorse the purchase of any commercial products or services mentioned in the publication. The support of the Australian Research Council (DP110101293) and the Centre of Advanced Nanomaterials of The University of Adelaide is also gratefully acknowledged.

The authors are grateful to Ms. Amani Ebrahim for her help in proposing the chemical reactions and Mr. Saeid Sedghizeinolhajloo for his help in conversion of the XPS data files. The Australian Microscopy and Microanalysis Research Facility (AMMRF) is gratefully acknowledged for access to the Kratos Axis-Ultra XPS instrument.

\section{Appendix A}

Supplementary data associated with this article can be found in the online version. 


\section{References}

[1] Daughton CG, Ternes TA. Pharmaceuticals and personal care products in the environment: Agents of subtle change. Environmental Health Perspectives Supplements. 1999;107(6):907-38.

[2] Stackelberg PE, Furlong ET, Meyer MT, Zaugg SD, Henderson AK, Reissman DB. Persistence of pharmaceutical compounds and other organic wastewater contaminants in a conventional drinking-watertreatment plant. Science of the Total Environment. 2004;329:99-113.

[3] Benotti MJ, Trenholm RA, Vanderford BJ, Holady JC, Stanford BD, Snyder SA. Pharmaceuticals and Endocrine Disrupting Compounds in U.S. Drinking Water. Environmental Science and Technology. 2009;43:597-603.

[4] Richardson SD, Postigo C. Drinking Water Disinfection By-products. In: Barceló D, ed. Emerging Organic Contaminants and Human Health: Springer Berlin Heidelberg 2012:93-137.

[5] Mohan D, Rajput S, Singh VK, Steele PH, Pittman Jr. CU. Modeling and evaluation of chromium remediation from water using low cost bio-char, a green adsorbent. Journal of Hazardous Materials. 2011;188(1-3):319-33.

[6] Inyang M, Gao B, Yao Y, Xue Y, Zimmerman AR, Pullammanappallil P, et al. Removal of heavy metals from aqueous solution by biochars derived from anaerobically digested biomass. Bioresource Technology. 2012;110(0):50-6.

[7] Jung C, Park J, Lim KH, Park S, Heo J, Her N, et al. Adsorption of selected endocrine disrupting compounds and pharmaceuticals on activated biochars. Journal of Hazardous Materials. 2013;263, Part 2(0):702-10. 
[8] Yu Z, Peldszus S, Huck PM. Adsorption characteristics of selected pharmaceuticals and an endocrine disrupting compound-Naproxen, carbamazepine and nonylphenol—on activated carbon. Water Research. 2008;42:2873-82.

[9] Mestre AS, Pires J, Nogueira JMF, Parra JB, Carvalho AP, Ania CO. Waste-derived activated carbons for removal of ibuprofen from solution: Role of surface chemistry and pore structure. Bioresource Technology. 2009;100:1720-6.

[10] Snyder SA, Adham S, Redding AM, Cannon FS, DeCarolis J, Oppenheimer J, et al. Role of membranes and activated carbon in the removal of endocrine disruptors and pharmaceuticals. Desalination. 2007;202:156-81.

[11] Ternes TA, Meisenheimer M, McDowell D, Sacher F, Brauch H-J, Haist-Gulde B, et al. Removal of Pharmaceuticals during Drinking Water Treatment. Environmental Science \& Technology. 2002;36(17):3855-63.

[12] Caliskana E, Gokturka S. Adsorption Characteristics of Sulfamethoxazole and Metronidazole on Activated Carbon. Separation Science and Technology. 2010;45(2):244-55.

[13] Ruiz B, Cabrita I, Mestre AS, Parra JB, Pires J, Carvalho AP, et al. Surface heterogeneity effects of activated carbons on the kinetics of paracetamol removal from aqueous solution. Applied Surface Science. 2010;256:5171-5.

[14] Galhetas M, Mestre AS, Pinto ML, Gulyurtlu I, Lopes H, Carvalho AP. Carbon-based materials prepared from pine gasification residues for acetaminophen adsorption. Chemical Engineering Journal. 2014;240:344-51. 
[15] Ji L, Liu F, Xu Z, Zheng S, Zhu D. Adsorption of Pharmaceutical Antibiotics on Template-Synthesized Ordered Micro- and Mesoporous Carbons. Environmental Science and Technology. 2010;44(8):3116-22.

[16] Ania CO, Bandosz TJ. Chemically Modified Nanoporous Carbons Obtained Using Template Carbonization Method. In: Levellyn P, ed. Fundamentals of Adsorption. Amsterdam: Elsevier 2006.

[17] Putra EK, Pranowo R, Sunarso J, Indraswati N, Ismadji S. Performance of activated carbon and bentonite for adsorption of amoxicillin from wastewater: Mechanisms, isotherms and kinetics. Water Research. 2009;43(9):2419-30.

[18] Tahar A, Choubert JM, Coquery M. Xenobiotics removal by adsorption in the context of tertiary treatment: a mini review. Environmental Science and Pollution Research. 2013;20:5085-95.

[19] Bui TX, Choi H. Adsorptive removal of selected pharmaceuticals by mesoporous silica SBA-15. Journal of Hazardous Materials. 2009;168(2-3):602-8.

[20] Jagiello J. Stable Numerical Solution of the Adsorption Integral Equation Using Splines. Langmuir. 1994;10(8):2778-85.

[21] Skinner WM, Prestidge CA, Smart RSC. Irradiation Effects During XPS Studies of Cu(II) Activation of Zinc Sulphide. Surface and Interface Analysis. 1996;24(9):620-6.

[22] von Oertzen GU, Skinner WM, Nesbitt HW, Pratt AR, Buckley AN. Cu adsorption on pyrite (100): $\mathrm{Ab}$ initio and spectroscopic studies. Surface Science. 2007;601(24):5794-9. 
[23] Serrano D, Lema JM, Omil F. Influence of the employment of adsorption and coprecipitation agents for the removal of PPCPs in conventional activated sludge (CAS) systems. Water and Science Technology. 2010;62(3):728-35.

[24] Li X, Hai FI, Nghiem LD. Simultaneous activated carbon adsorption within a membrane bioreactor for an enhanced micropollutant removal. Bioresource Technology. 2011;102:5319-24.

[25] Bandosz TJ. Effect of pore structure and surface chemistry of virgin activated carbons on removal of hydrogen sulfide. Carbon. 1999;37(3):483-91.

[26] Adib F, Bagreev A, Bandosz TJ. Analysis of the Relationship between H2S Removal Capacity and Surface Properties of Unimpregnated Activated Carbons. Environmental Science and Technology. 2000;34:686-92.

[27] Ania CO, Bandosz TJ. Importance of Structural and Chemical Heterogeneity of Activated Carbon Surfaces for Adsorption of Dibenzothiophene. Langmuir. 2005;21(17):7752-9.

[28] Farrell J, Naisbitt DJ, Drummond NS, Depta JPH, Vilar FJ, Pirmohamed M, et al. Characterization of Sulfamethoxazole and Sulfamethoxazole Metabolite-Specific TCell Responses in Animals and Humans. Journal of Pharmacology and Experimental Therapeutics. 2003;306:229-37.

[29] Figueiredo JL, Pereira MFR, Freitas MMA, Órfão JJM. Modification of the surface chemistry of activated carbons. Carbon. 1999;37(9):1379-89.

[30] Szymański GS, Karpiński Z, Biniak S, Świątkowski A. The effect of the gradual thermal decomposition of surface oxygen species on the chemical and catalytic properties of oxidized activated carbon. Carbon. 2002;40(14):2627-39. 
[31] Stöhr B, Boehm HP, Schlögl R. Enhancement of the catalytic activity of activated carbons in oxidation reactions by thermal treatment with ammonia or hydrogen cyanide and observation of a superoxide species as a possible intermediate. Carbon. 1991;29(6):707-20.

[32] Im J-K, Son H-S, Kang Y-M, Zoh K-D. Carbamazepine Degradation by Photolysis and Titanium Dioxide Photocatalysis. Water Environment Research. 2012;84(7):554-61.

[33] Schaber PM, Colson J, Higgins S, Thielen D, Anspach B, Brauer J. Thermal decomposition (pyrolysis) of urea in an open reaction vessel. Thermochimica Acta. 2004;424(1-2):131-42.

[34] Kruusenberg I, Alexeyeva N, Tammeveski K. The pH-dependence of oxygen reduction on multi-walled carbon nanotube modified glassy carbon electrodes. Carbon. 2009;47(3):651-8.

[35] Smith BC. Infrared Spectral Interpretation: A Systematic Approach: Taylor \& Francis; 1998.

[36] Albert S, Albert KK, Quack M. High-Resolution Fourier Transform Infrared Spectroscopy. In: Quack M, ed. Handbook of High-resolution Spectroscopy. Laboratorium für Physikalische Chemie, ETH Zürich, Zürich, Switzerland: John Wiley and Sons. Inc 2011.

[37] Bandosz TJ, Jagiello J, Contescu C, Schwarz JA. Characterization of the surfaces of activated carbons in terms of their acidity constant distributions. Carbon. 1993;31(7):1193-202.

[38] Krygowski TM, Szatyłowicz H, Zachara JE. How H-bonding Modifies Molecular Structure and $\pi$-Electron Delocalization in the Ring of Pyridine/Pyridinium 
Derivatives Involved in H-Bond Complexation†. The Journal of Organic Chemistry. 2005;70(22):8859-65. 
SUPPLEMENTARY INFORMATION

The effects of activated carbon surface features on the reactive adsorption of

\section{carbamazepine and sulfamethoxazole}

Lilja Nielsen ${ }^{\text {a }}$, Mark J. Biggs ${ }^{\text {b }}$, William Skinner ${ }^{\text {c, Teresa J. Bandosz }}{ }^{\text {a,* }}$

${ }^{\mathrm{a}}$ The City College of New York and the Graduate School of CUNY

Department of Chemistry and Department of Earth System Science

160 Convent Ave, New York, NY 10031

$\mathrm{b}$ The University of Adelaide

School of Chemical Engineering

Adelaide, SA 5005, Australia

${ }^{\mathrm{c}}$ University of South Australia

Ian Wark Research Institute and The ARC Special Research Centre for Particle and Material

Interfaces, Mawson Lakes, Adelaide, SA 5095, Australia

\footnotetext{
*Whom correspondence should be addressed to. E-mail:tbandosz@ccny.cuny.edu; Tel.:(212)650-6017; Fax (212) 650-6107
} 


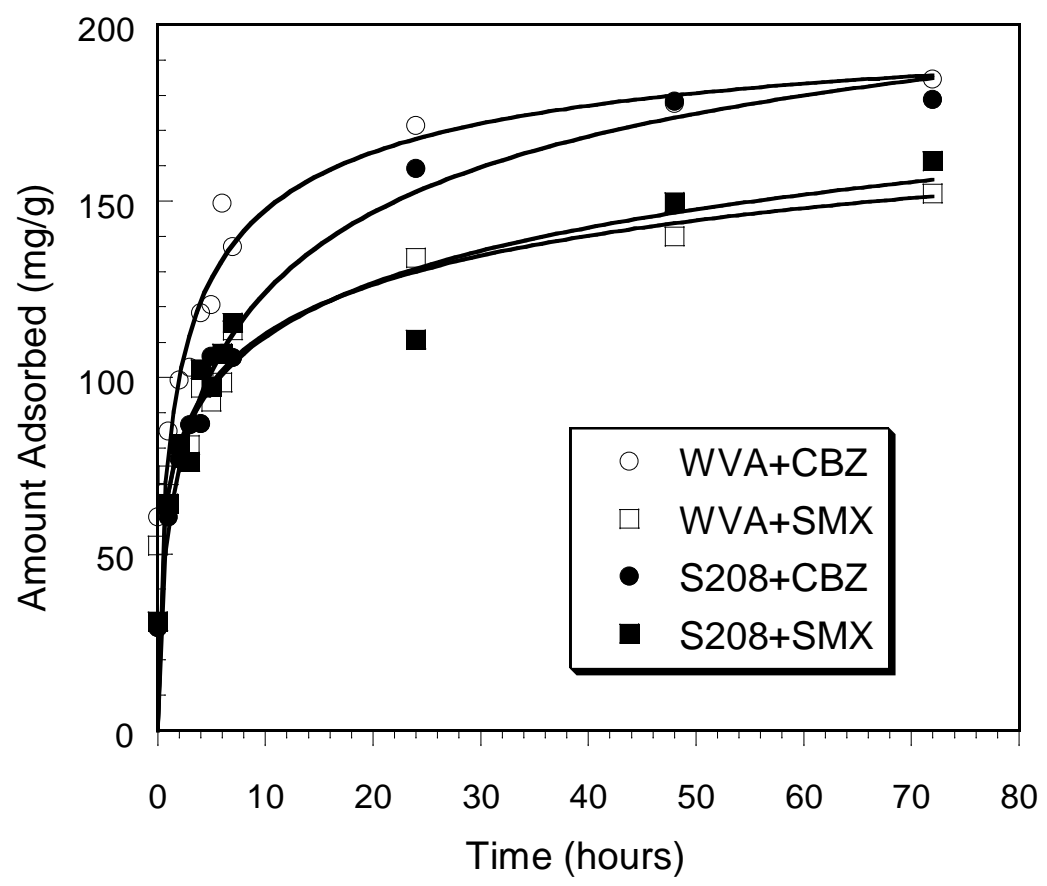

Fig. S1. Kinetics curves for carbamazepine (CBZ) and sulfamethoxazole (SMX) adsorption on the surface of carbon adsorbents WVA and S208. 


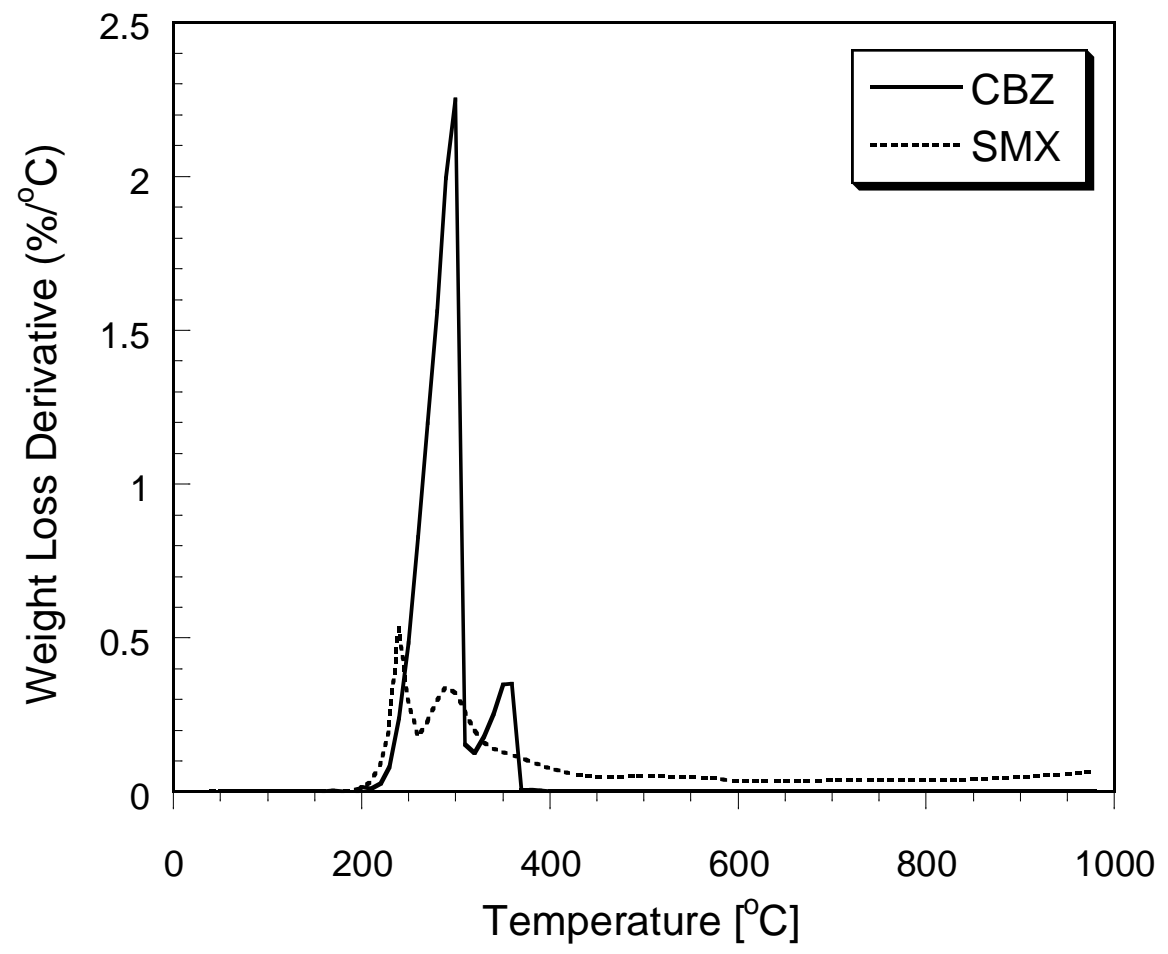

Fig. S2. DTG curves for carbamazepine and sulfamethoxazole in nitrogen. 
Table S1 . Peak position and numbers of groups (in parentheses; [mmol/g]).

\begin{tabular}{|c|c|c|c|c|c|c|c|c|c|}
\hline Sample & $\mathrm{pH}$ & $\mathrm{pK}_{\mathrm{a}}$ 4-5 & $\mathrm{pK}_{\mathrm{a}}$ 5-6 & $\mathrm{pK}_{\mathrm{a}}$ 6-7 & $\mathrm{pK}_{\mathrm{a}}$ 7-8 & $\mathrm{pK}_{\mathrm{a}} 8-9$ & $\mathrm{pK}_{\mathrm{a}}$ 9-10 & $\mathrm{pK}_{\mathrm{a}} 10-11$ & All \\
\hline WVA1100 & 7.41 & $\begin{array}{c}4.76 \\
(0.102)\end{array}$ & & $\begin{array}{c}6.10 \\
(0.077)\end{array}$ & $\begin{array}{c}7.10 \\
(0.139)\end{array}$ & $\begin{array}{c}8.37 \\
(0.046)\end{array}$ & $\begin{array}{c}9.26 \\
(0.066)\end{array}$ & $\begin{array}{c}10.24 \\
(0.150)\end{array}$ & 0.580 \\
\hline WVA1100+CBZ & 6.47 & $\begin{array}{c}4.44 \\
(0.113)\end{array}$ & & $\begin{array}{c}6.10 \\
(0.156)\end{array}$ & $\begin{array}{c}7.21 \\
(0.082)\end{array}$ & $\begin{array}{l}8.76 \\
(0.77)\end{array}$ & $\begin{array}{c}9.77 \\
(0.112)\end{array}$ & & 0.541 \\
\hline WVA100+SMX & 6.41 & & $\begin{array}{c}5.22 \\
(0.141)\end{array}$ & $\begin{array}{c}6.70 \\
(0.172)\end{array}$ & $\begin{array}{c}7.74 \\
(0.212)\end{array}$ & $\begin{array}{c}8.85 \\
(0.208)\end{array}$ & & $\begin{array}{c}10.01 \\
(0.289)\end{array}$ & 1.023 \\
\hline S208C & 7.52 & & & $\begin{array}{c}6.12 \\
(0.077)\end{array}$ & $\begin{array}{c}7.90 \\
(0.066)\end{array}$ & & $\begin{array}{c}9.46 \\
(0.122)\end{array}$ & $\begin{array}{l}10.52 \\
(0.401)\end{array}$ & 0.665 \\
\hline S208C + CBZ & 7.50 & $\begin{array}{c}4.76 \\
(0.053)\end{array}$ & & & $\begin{array}{c}7.80 \\
(0.060)\end{array}$ & & $\begin{array}{c}9.92 \\
(0.113)\end{array}$ & & 0.226 \\
\hline S208C + SMX & 7.28 & & & $\begin{array}{c}6.89 \\
(0.100)\end{array}$ & & $\begin{array}{c}8.88 \\
(0.073)\end{array}$ & & $\begin{array}{c}10.31 \\
(0.339)\end{array}$ & 0.511 \\
\hline
\end{tabular}




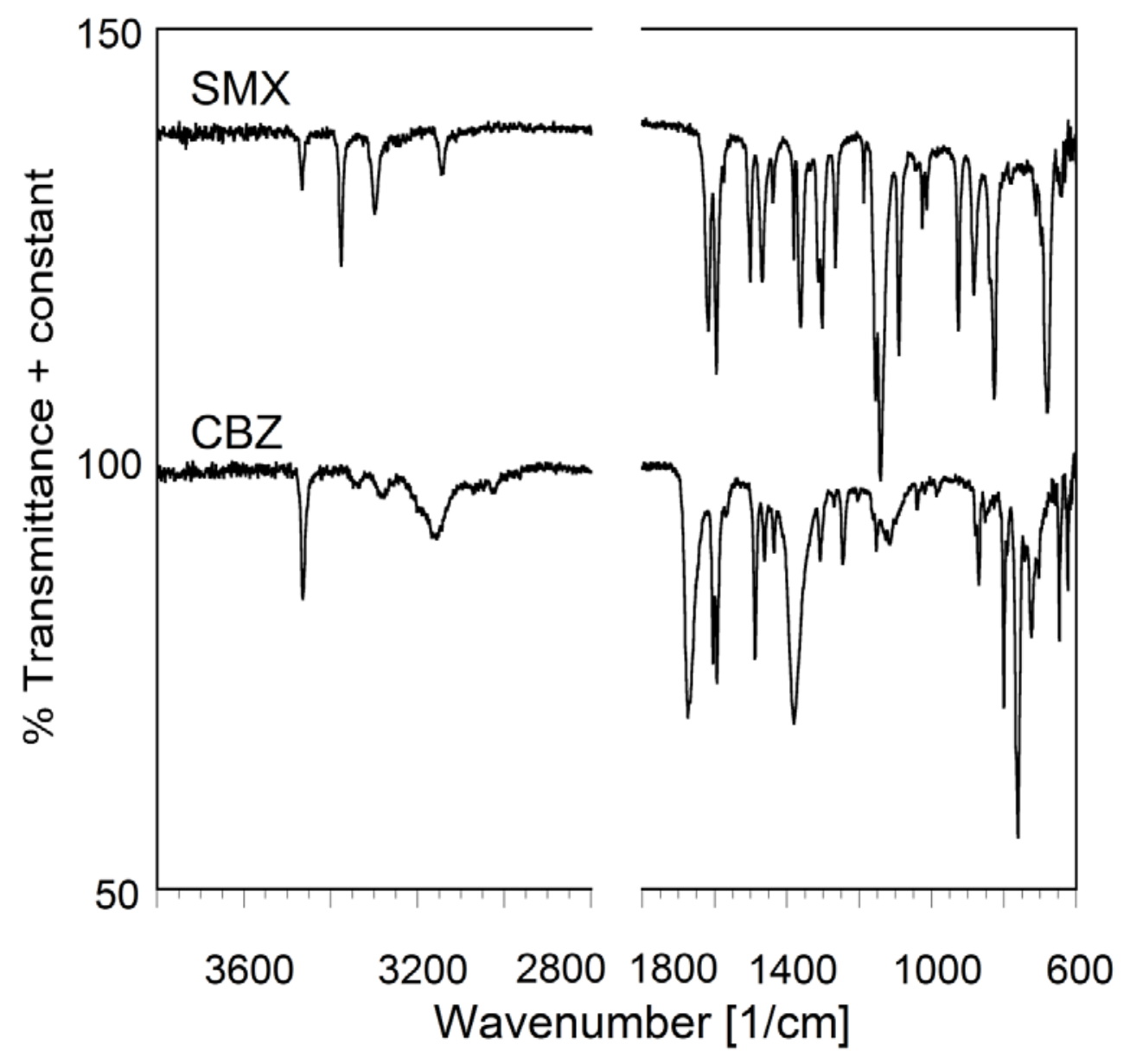

Fig. S3. FTIR spectra for carbamazepine and sulfamethoxazole 